NASA Technical Memorandum 88912

AIAA-87-0420

\title{
Analysis of Viscous Transonic Flow Over Airfoil Sections
}

(NASA-1M-88912) ANALYSIS CH VISCCUS

THANSCNIC FLOW OVER AIBECIL SFCTICNS (NASA)

N87-17001

$3<\mathrm{p}$

$\operatorname{CSCL} 20 \mathrm{D}$

\section{G $3134-43900$}

Dennis L. Huff

Lewis Research Center

Cleveland, Ohio

and

Jiunn-Chi Wu and L.N. Sankar

Georgia Institute of Technology

Atlanta, Georgia

Prepared for the

25th Aerospace Sciences Meeting

sponsored by the American Institute of Aeronautics and Astronautics

Reno, Nevada, January 12-15, 1987 


\title{
ANALYSIS OF VISCOUS TRANSONIC FLOW OVER AIRFOIL SECTIONS
}

\author{
Dennis L. Huff \\ National Aeronautics and Space Administration \\ Lewis Research Center \\ Cleveland, Ohio 44135 \\ Jiunn-Chi* and L.N. Sankar** \\ Georgia Institute of Technology \\ School of Aerospace Engineering \\ At lanta, Georgia 30332
}

\section{Abstract}

A full Navier-Stokes solver has been used to model transonic flow over three airfoil sections. The method uses a two-dimensional, implicit, conservative finite difference scheme for solving the compressible Navier-Stokes equations. Results are presented as prescribed for the Viscous Transonic Airfoil Workshop to held at the AIAA 25th Aerospace Sciences Meeting. The NACA 0012, RAE 2822 and "Jones" airfoils have been investigated for both attached and separated transonic flows. Predictions for pressure distributions, loads, skin friction coefficients, boundary layer displacement thickness and velocity profiles are included and compared with experimental data when possible. Overall, the results are in good agreement with experimental data.

\begin{tabular}{|c|c|}
\hline \multicolumn{2}{|r|}{ Nomenclature } \\
\hline a & angle of attack, $\alpha$ (deg) \\
\hline c & chordlength \\
\hline CD & drag coefficient \\
\hline$C F$ & $\begin{array}{l}\text { skin friction coefficient base on } \\
\text { free-stream conditions }\end{array}$ \\
\hline $\mathrm{CL}$ & lift coefficient \\
\hline CLmax & maximum lift coefficient \\
\hline$C P$ & pressure coefficient \\
\hline$D C L / D A$ & slope of linear portion of $C L$ versus a \\
\hline DEL & $\begin{array}{l}\text { inverse of the number of upper surface } \\
\text { grid points }\end{array}$ \\
\hline DSTAR & $\begin{array}{l}\text { boundary layer displacement thickness } \\
\text { (chords) }\end{array}$ \\
\hline & $=\int_{0}^{e}\left(1-\frac{\rho u}{\rho U e}\right) d s$ \\
\hline e & total energy of the fluid per unit volume \\
\hline J & Jacobian of transformation \\
\hline Minf & free-stream Mach number \\
\hline
\end{tabular}

*Graduate Research Assistant; student member AIAA. **Associate Professor; member AIAA.
$R \quad$ average distance to outer boundary from leading edge

RE Reynolds number based on chord

s arclength of a grid line in the n-direction

Se arclength of a grid line from the airfoil surface to the node with a velocity of Ve

u,v cartesian velocities normalized by the speed of sound

Ue maximum total velocity from the airfoil surface along a grid line

Uinf free-stream velocity

$x, y \quad$ cartesian coordinates normalized by chordlength

XS shock location on the upper surface (chords)

$5 \quad$ chordwise direction of transformed coordinate system

n normal direction of transformed coordinate system

o density

$\tau$ time variable

$\Delta n$ distance of the first grid line off the airfoil surface (chords)

\section{Introduction}

In recent years, many computer programs have been written that predict the transonic flow properties around an airfoil. The purpose of these codes is to help in the design of airfoils, such as those found on helicopters, propellers, wings, and turbomachinery. Accurate prediction of the flow field is necessary for performance, acoustic and aeroelastic analyses. In order to determine the quantitative ability of these codes, a workshop has been organized to compare a variety of flow solvers. These are all capable of producing airfoil solutions over a wide range of flow conditions, including both attached and separated transonic flow. The predictions from individual flow solvers are to be presented at the Viscous Transonic Airfoil Workshop in coordination with the AIAA 25th Aerospace Sciences Meeting. The results will be combined for the Fluid Dynamics Meeting six months later. The present study shows results from one of the flow solvers to be presented at the workshop. An unsteady, two-dimensional, full 
Navier-Stokes solver is used to compute the flowfield around the three airfoils shown in Fig. 1 . The required plots for the workshop are summarized in Table 1. Results for these test cases are presented to help determine the quantitative ability of the present Navier-Stokes solver by comparing the results with experimental data.

\section{Numerical Procedure}

The program addresses the two-dimensional flow problem by solving the unsteady, two-dimensional, Reynolds-averaged, compressible Navier-Stokes equations on a body-fitted coordinate system in strong conservation form using an ADI procedure. The formulation has been described in Ref. 1 , and only a brief outline is given here. All of the calculations were performed in a body-fitted coordinate system $(\xi, \eta, \tau)$ which is linked to the cartesian coordinates according to the following one-to-one relationships:

$$
\begin{aligned}
\xi & =\xi(x, y, t) \\
\eta & =n(x, y, t) \\
\tau & =t
\end{aligned}
$$

The Jacobian of the transformation is given by

$$
J=\xi_{x} n_{y}-n_{x} \xi_{y}=\frac{1}{\left(x_{\xi} y_{n}-x_{n} y_{\xi}\right)}
$$

and the metrics of the transformation are given by the relationship:

$$
\begin{gathered}
\xi_{x}=J y_{n} \\
\xi_{y}=-J x_{n} \\
\eta_{x}=-J y_{\xi} \\
\eta_{y}=J x_{\xi}
\end{gathered}
$$

Standard central differences were used to compute the quantities such as $x_{F}, y_{F}$ etc., and

these quantities in turn were used in Eqs. (2) and (3) to compute $\xi_{x}, \xi_{y}$, etc. At the

boundaries, three-point one-sided differences were used to compute the metrics. The far field boundaries are assumed to be undisturbed; except at the downstream boundary, where the velocities $(u, v)$ and the entropy are extrapolated from the interior.

In this coordinate system, the two-dimensional unsteady Navier-Stokes equations may be written as follows:

$$
\hat{q}_{\tau}+\hat{F}_{\xi}+\hat{G}_{\eta}=\hat{R}_{\xi}+\hat{S}_{\eta}
$$

where

$$
\hat{q}=J^{-1}\{\rho, \rho u, \rho v, \text { e }\}
$$

and $\rho$ is the fluid density; $u$ and $v$ are the cartesian components of fluid velocity; $e$ is the total energy of the fluid per unit volume. The quantities $\hat{F}, \hat{G}, \hat{R}$, and $\hat{S}$ are given by:

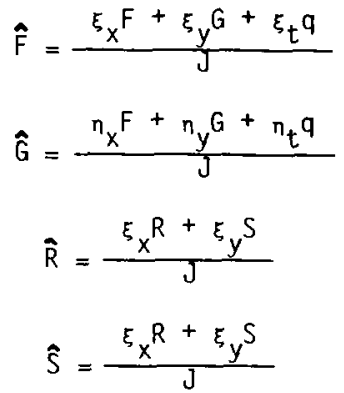

The terms $F, R$, etc. are the standard flux and viscous stress terms along the $x$-direction, in the original cartesian form. The terms $G$ and $S$ are likewise the flux and viscous terms along the $y$-direction.

An eddy viscosity concept is used to model the turbulent momentum and energy transfer. The entire flow field is assumed to be turbulent.

Since Eqs. (4) and (5) are coupled to each other, and are highly nonlinear, a stable, efficient solution procedure is required. In the present work the Beam-Warming algorithm, 5 as implemented by Steger, 6 was followed with some changes made to the artifical dissipation terms to a void shock overshoots, and to avoid excessive smearing of embedded vortices. The viscous terms were lagged by one time step, while other terms in the governing equations were treated implicity, at the current time level. The nonlinear terms are split, with parts treated either implicitly or lagged in time. The details of the discretization procedure, the artifical dissipation terms used and several benchmark calculations are presented in Ref. 1 .

The original algebraic grid generator used by Sankar and Tangl has been replaced with the GRAPE code (GRids about Airfoils using Poisson's Equations) developed by Sorenson. 2 This gives the Navier-Stokes solver greater flexibility to investigate the effects of grid changes, as required by the workshop. For most cases, a 157 by $58 \mathrm{C}$-grid is used with 60 nodes defining the wake. This leaves 97 nodes wrapped around the upper and lower surfaces. The distance off the airfoil surface to the first grid line is 0.00005 chordlengths. The GRAPE code allows the user to vary the clustering of the grid lines near the airfoil surface. A typical base grid used in this study is shown in Fig. 2 .

Al] runs were done on the CRAY-XMP at the NASA Lewis Research Center. The number of iterations required for convergence range between 1500 and 5000 , depending on the flow conditions. The respective vectorized CPU times were 519 and $1730 \mathrm{sec}$. The calculations continue until the spatialmaximum density residual drops by four orders of magnitude from the initial condition. The solver has been vectorized so that the ratio of scalar CPU time to vectorized CPU time is about 2.68 . The total calculation time is approximately $3.8 \times 10^{-5}$ sec per point per iteration. The maximum memory required is 960 kwords using a 157 by 58 grid. 


\section{Results}

Case A: NACA 0012 Airfoil

A study of the grid is necessary to determine the sensitivity of the predictions to variations in the grid. The present results include both grid refinement and boundary position comparisons. Define a grid refinement parameter, DEL, to be the inverse of the number of upper surface grid points. For the 157 by 58 base grid, the value of DEL is 0.021 . A variation in DEL represents a proportional change in the grid size from the base grid. The outer boundary position remains fixed at six chordlengths. (This ratio is equally enforced in the wake region.) Figures 3 and 4 show lift and drag predictions as a function of $D E L$ for the test case: $M I N F=0.70, a=1.49^{\circ}$ and $R E=9.0$ million. The asymptotic behavior for loads as DEL becomes small suggests that the 157 by 58 base grid gives reasonable predictions.

Next, the outer boundary position $(R)$ was varied from 2 to 20 chordlengths away from the leading edge using a 157 by 58 grid. Figures 5 and 6 justify the base grid results for lift and drag predictions. When $R$ equals 15 and 20 , the grid spacing near the airfoil surface increases significantly. This explains the nonasymptotic behavior of the drag predictions in Fig. 6 as $R$ increases.

The distance of the first grid line off the airfoil surface $(\Delta n)$ must be carefully chosen to properly model the boundary layer. Figure 7 shows how this parameter can effect the pressure distributions for three values of $\Delta n: 0.00002$, 0.00005 , and 0.0005 . When $\Delta n=0.0005$, the shock is smeared and the magnitude of pressure is higher aft of the shock. A value of $\Delta n=0.00005$ appears to give satisfactory predictions and is used in the base grid. The base grid ( 157 by 58 , $R=6$ chords, $\Delta n=0.00005$ chords) is now defined for the NACA 0012 airfoil and will be used for the remainder of the test cases.

Figures 8 through 10 show pressure distributions over the NACA 0012 airfoil for several ranges of velocity and angle of attack. Results for two values of angle of attack are plotted along with experimental data from Harris. 3 The higher angle corresponds to the value used in the experiment, where the lower angle is corrected for wind tunnel wall interference (as suggested in Ref. 3 ). Results show that wind tunnel wall interference can significantly change the behavior of the pressure distributions. The corrected angle of attack tends to give better agreement with experiment. The overall agreement is very good for test cases in Figs. 8 and 9 . In the case of a strong shock, the predicted shock location is about 0.10 chordlengths aft of the experimentally determined shock location (see Fig. 10). The flow solver requires as input a value for the artificial (numerical) damping. It is important to minimize this value in order to properly model the Navier-Stokes equations. For the test case in Fig. 10, higher numerical damping tends to make the predicted shock location appear to be closer to the experimental shock location. Higher numerical damping also results in more shock smearing.

A plot of CL versus $a(a)$ is presented in Fig. 11 for Minf $=0.70$ and $R E=9.0 \mathrm{million}$.
The predictions are good for flow conditions where experimental data exists. A variable time step'is used in steady-state solutions to decrease the convergence time. However, when unsteady flow exists, a time accurate solution is required. Two time accurate predictions are included in Fig. 11 for a equal to 5.86 and $6.5^{\circ}$. Unsteady flow due to separation is expected at these angles, but predictions between the variable time step and time accurate cases appear to be nearly identical. Plots of $C L$ versus $C D$ and $C D$ versus Minf are shown in Figs. 12 and 13. The overall agreement with experiment is good.

Figure 14 shows how the shock location moves aft as the free-stream Mach number increases ( $a=0.0^{\circ}, R E=9.0$ million). Predictions for CLmax versus Minf are presented in Fig. 15. All runs used to determine CLmax were time accurate with increments for $a$ of $0.5^{\circ}$. The magnitude of the prediction for CLmax is expected to be somewhat inaccurate due to this discretization of $\alpha$. Figure 16 shows how the slope of the linear portion of $\mathrm{CL}$ versus a is predicted to change with Minf.

\section{Case B: RAE 2822 Airfoil}

Results from two test cases are presented for the RAE 2822 airfoil and compared with experimental data from Cook, McDanald and Firman. 4 The effect of the wind tunnel interference is not easily determined. Hence, a range of flow conditions were tried to match the pressure distributions. A "matched" pressure distribution is the best agreement of the predictions with the experimental data that can be found by adjusting the Mach number and the angle of attack. In cases where a strong shock exists, a good "matched" pressure distribution is difficult and only an overall agreement can be estimated. The experimental pressure distributions are shown in Fig. 17 for Minf $=0.725, a=2.92^{\circ}$ and $R E=6.5$ million. Predictions for Minf $=0.73$ and $a=2.79^{\circ}$ are plotted from the flow solver using a 157 by 58 base grid similiar to the base grid used in the NACA 0012 airfoil analysis. (The conclusions from the grid study done for the NACA 0012 airfoil were assumed to be the same for both the RAE 2822 and Jones airfails). The agreement is very good for most regions on the airfoil. The expansion near the leading edge on the upper surface shown in the experimental data is probably due to the transition location being $f$ ixed at $x / c=0.03$. This is not modeled in the flow solver since the entire flow field is assumed to be turbulent. The integrated lift and drag coefficients from the experiment are respectively 0.7433 and 0.0127 , which correspond to 0.7423 and 0.0134 from the Navier-Stokes code.

The calculation of displacement thickness, DSTAR, is not straight forward. The definition of edge velocity, Ue, is not as well defined for an airfoil as it is for a flat plate. Separated flow and curvature from the inviscid velocity variation further complicates the computation. For the present analysis, the edge velocity used to calculate DSTAR is the first maximum total velocity away from the airfoil surface. The boundary layer is the arclength of the grid ine measured from the airfoil surface to the node identified as having the velocity, Ue. Figure 18 shows the predicted DSTAR along the upper surface of the current test case. The boundary layer becomes thicker aft of 
the shock, as expected. The skin friction coefficient decreases along the upper surfaces, as shown in Fig. 19. Velocity profiles are shown for two locations on the upper surface: $x / c=0.319$ and $x / c=0.956$. The magnitudes of the velocities used to calculate U/Uinf are taken from the component of velocity in the free-stream direction. The results are presented in Figs. 20 and 21.

The second test case for the RAE 2822 airfoil corresponds to the following experimental flow conditions: $M I N F=0.75, a=3.19^{\circ}$ and $R E=6.2$ million. The "matched" conditions selected for the flow solver are: Minf $=0.755$ and $a=3.03^{\circ}$. A comparison of the pressure distributions is shown in Fig. 22. Again, minor discrepancies exist for the upper surface pressure near the leading edge. The shock location is predicted slightly aft of the experiment. Recall that this trend was also observed for NACA 0012 airfoil for the test case with a strong shock (see Fig. 10). The flow behind a strong shock is unsteady due to separation, which challenges the turbulence model to properly estimate the eddy viscosity. Coakley 7 has shown how important the turbulence model can be for this test case. He found that predictions using the Baldwin-Lomax model (used in the present solver) causes the shock to be located aft of experiment, while predictions using other turbulence models improve the agreement.

The displacement thickness of the boundary layer on the upper surface is shown in Fig. 23. Agreement between analys is and experiment is good in the region forward of the shock. Figure 24 shows the corresponding skin friction coefficient distribution. Two separated regions are predicted near the shock and near the trailing edge. Velocity profiles at $x / c=0.75$ and $x / c=0.897$ are presented in Figs. 25 and 26 . The predictions appears to show attached flow, but the scale chosen for the plots does not show that the flow is predicted to be separated very close to the airfoil surface. The separation regions near the airfoil surface are shown best in the skin friction coefficient distribution. The sonic line prediction is shown if Fig. 27 as a dotted line.

\section{Case C: Jones Airfoi?}

The last airfoil investigated in this study is the Jones "supercritical-type" airfoil, developed by R.T. Jones of the NASA Ames Research Center. This airfoil was selected for the Viscous Transonic Airfoil Workshop because it has not been widely tested either numerically or experimentally and serves as a good "blind" calculation for flow solvers.

Predictions for $\mathrm{CL}$ versus $\alpha$ and $\mathrm{CL}$ versus $C D$ are shown in Figs. 28 and 29. The lift curve slope begins to drop, but never drops enough to give a good CLmax prediction. The solution residuals become oscillatory at higher angles of attack, which usually indicates unsteady flow. Time accurate solutions were tried for $a=6.5^{\circ}$ and $a=7.0^{\circ}$. A slight drop in the lift coefficients is observed, as shown in Fig. 28. A plot of predicted $C D$ versus Minf is shown in Fig. 30 for $a=0.0^{\circ}$.

A supercritical test case was run for Minf $=0.75, a=2.0^{\circ}$ and $R E=9.0$ million. The pressure distributions in Fig. 31 shows a strong shock predicted on the upper surface near the forty-percent chord location. The boundary layer thickens near the shock, as shown in Fig. 32. The sudden rise in the displacement thickness near the trailing edge is due to the rapid change in the edge velocity location in the chordwise direction. The method for calculating displacement thickness uses the first maximum total velocity off the airfoil surface. If the velocity profile is very complicated, as it is near the trailing edge, the velocity is not easily determined. The plot is dotted in this region to represent the uncertainty of the DSTAR calculation. Skin friction coefficients and velocity profiles at $x / c=0.613$ and $x / c=0.897$ are presented in Figs. 33 through 35 .

Results are also presented for a separated, supercritical case (Minf $=0.85, a=2.0^{\circ}$ ) and summarized in Figs. 36 through 40 . In this case, shocks are predicted on both the upper and lower surfaces. Separation occurs from about $x / c=0.80$ to the trailing edge on the upper surface. Again, the displacement thickness calculations in this region are not well defined.

\section{Conclusion}

A full Navier-Stokes flow solver has been evaluated for modeling transonic flow over the NACA 0012, RAE 2822 and Jones airfoil sections. A 157 by 58 C-grid, with an average outer boundary distance of six chords appears to be adequate for most flow conditions. Comparisons with experimental data have been shown for both the NACA 0012 and RAE 2822 airfoils. In cases with strong shocks and separated flow, the predicted shock locations are found to be aft of the experimentally determined locations. Separation near the shock and the trailing edge is also predicted for these cases. Results for lift coefficient versus $\alpha$ predict a loss in lift at higher angles of attack and require a time-accurate solution when the flow is unsteady. Wind tunnel interference corrections show improved agreement between the predicted and experimental pressure distributions. Overa11, the results are in good agreement with experimental data.

\section{Acknowledgements}

The authors wish to thank Dr. Rodrick V. Chima of the NASA Lewis Research Center for his heip with the GRAPE grid generator.

\section{References}

1. Sankar, L.N. and Tang, W., "Numerical Solution of Unsteady Viscous Flow Past Rotor Sections," AIAA Paper 85-0129, Jan. 1985.

2. Sorenson, R.L., "A Computer Program to Generate Two-Dimensional Grids About Airfoils and Other Shapes by the Use of Poisson's Equation, "NASA TM-81198, 1980.

3. Harris, C.D., "Two-Dimensional Aerodynamic Characteristics of the NACA 0012 Airfoil in the Langley 8-foot Transonic Pressure Tunnel, "NASA TM-81927, 1981. 
4. Cook P.H., McDonald M.A., and Firman M.C.P., "Aerofoil RAE 2822-Pressure Distributions, and Boundary Layer and Wake Measurements,"

Experimental Data Base for Computer Program Assessment, AGARD-AR-138, J. Barche, ed., AGARD, France, 1979, pp. A6-1 to A6-77.

5. Beam, R.M. and Warming, R.F., "An Implicit Factored Scheme for the Compressible NavierStokes Equations," AIAA Journal, Vol. 16, No.4, Apr. 1978, pp. 393-402.
6. Steger, J.L., "Implicit Finite Difference Simulation of Flow about Arbitrary TwoDimensional Geometries," AIAA Journal, Vol. 16, no.7, Juily 1978, pp. 679-686.

7. Coakley, T.J., "Impact of Turbulence Modeling on Numerical Accuracy and Efficiency of Compressible Flow Simulations," NASA TM-88333, 1986. 
TABLE 1. - TEST CASES SPECIFIED BY THE VISCOUS TRANSONIC AIRFOIL WORKSHOP

\begin{tabular}{|c|c|c|c|}
\hline \multicolumn{4}{|c|}{ NACA 0012 airfoil (RE $=9.0$ million) } \\
\hline CP & versus & $x / c$ & Minf $=0.70, a=1.86^{\circ}$ \\
\hline$C P$ & versus & $x / c$ & Minf $=0.55, a=9.86^{\circ}$ \\
\hline $\mathrm{CP}$ & versus & $x / c$ & Minf $=0.799, a=2.86^{\circ}$ \\
\hline$C L$ & versus & a & Minf $=0.70, a=1,3,5,6$, \\
\hline $\mathrm{CL}$ & versus & CD & Minf $=0.70, a=0,1,3,5$ \\
\hline CD & versus & Minf & $a=0$, Minf $=0.5$ \\
\hline CL & versus & DEL & Minf $=0.70, a=1.86^{\circ}$ \\
\hline CD & versus & DEL & Minf $=0.70, a=1.86^{\circ}$. \\
\hline $\mathrm{CL}$ & versus & $\mathrm{R}$ & Minf $=0.70, a=1.86$ \\
\hline CD & versus & $\mathrm{R}$ & Minf $=0.70, a=1.86$ \\
\hline XS & versus & Mint & $\mathrm{a}=0$, Mint $=0.8$ to 1.1 \\
\hline & $\begin{array}{ll}\text { lax } & \text { ver } \\
\text { IDA ver }\end{array}$ & $\begin{array}{l}\text { sus Mint } \\
\text { sus Minf }\end{array}$ & $\begin{array}{l}\text { Mint }=0,3,0.5,0.0,0.1,0.8 \\
a=0,5 \text { to } 1.1\end{array}$ \\
\hline
\end{tabular}

RAE 2822 Airfoil

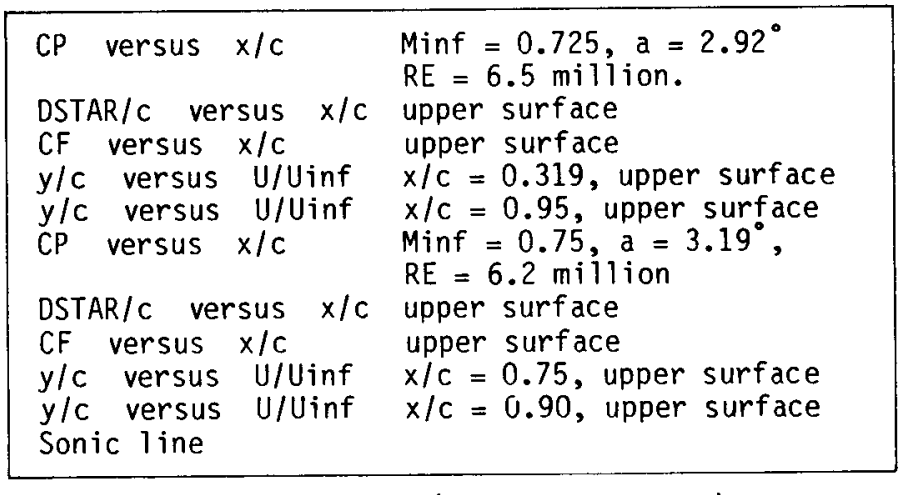

Jones airfoil ( $R E=9.0 \mathrm{million})$

\begin{tabular}{|c|c|}
\hline $\begin{array}{l}C L \text { versus a } \\
C L \text { versus } C D \\
C D \text { versus Minf } \\
C P \text { versus } x / C \\
D S T A R / C \text { versus } x / c \\
C F \text { versus } x / C \\
y / C \text { versus } U / U \text { inf } \\
y / c \text { versus U/Uinf } \\
C P \text { versus } x / C \\
D S T A R / C \text { versus } \times / c \\
C F \text { versus } x / C \\
y / C \text { versus U/Uinf } \\
y / c \text { versus U/Uinf }\end{array}$ & $\begin{array}{l}\text { Minf }=0.7, a=0,1,3,5,6,7^{\circ} \\
\text { Minf }=0.7, a=0,1,3,5,6,7^{\circ} \\
a=0, \text { Minf }=0.5 \text { to } 1.1 \\
\text { Minf }=0.75, a=2.0^{\circ} \\
\text { upper surface } \\
\text { upper surface } \\
x / c=0.6, \text { upper surface } \\
x / c=0.9, \text { upper surface } \\
\text { Minf }=0.85, a=2.0^{\circ} \\
\text { upper surface } \\
\text { upper surface } \\
x / c=0.6, \text { upper surface } \\
x / c=0.9, \text { upper surface }\end{array}$ \\
\hline
\end{tabular}



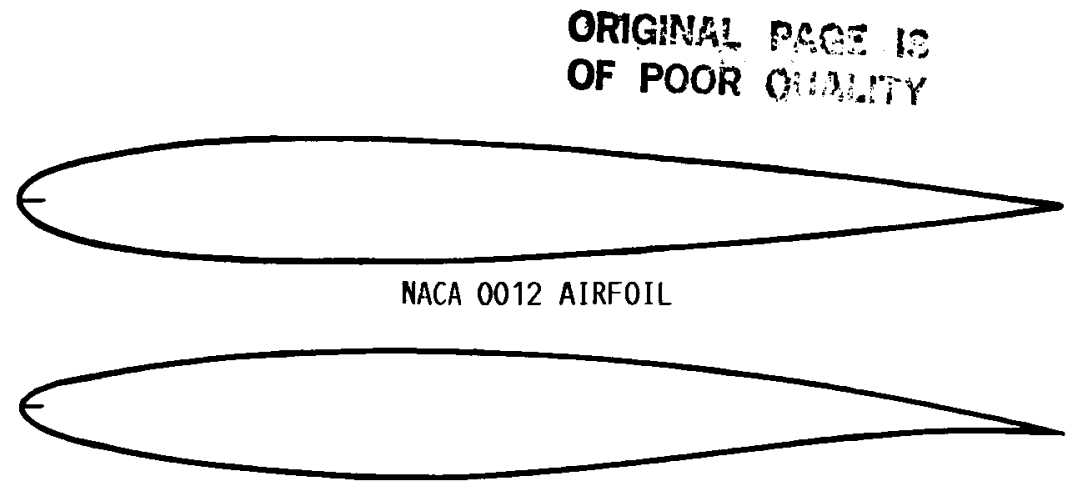

RAE 2822 AIRFOIL

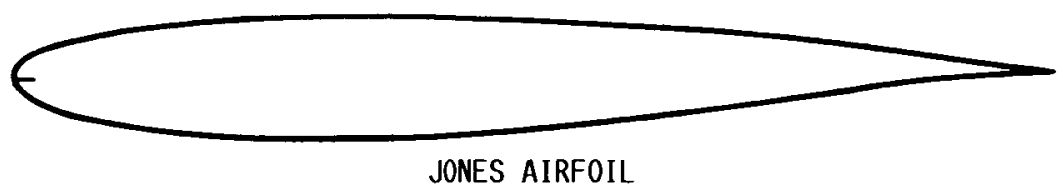

FIGURE 1.- AIRFOIL SECTIONS.

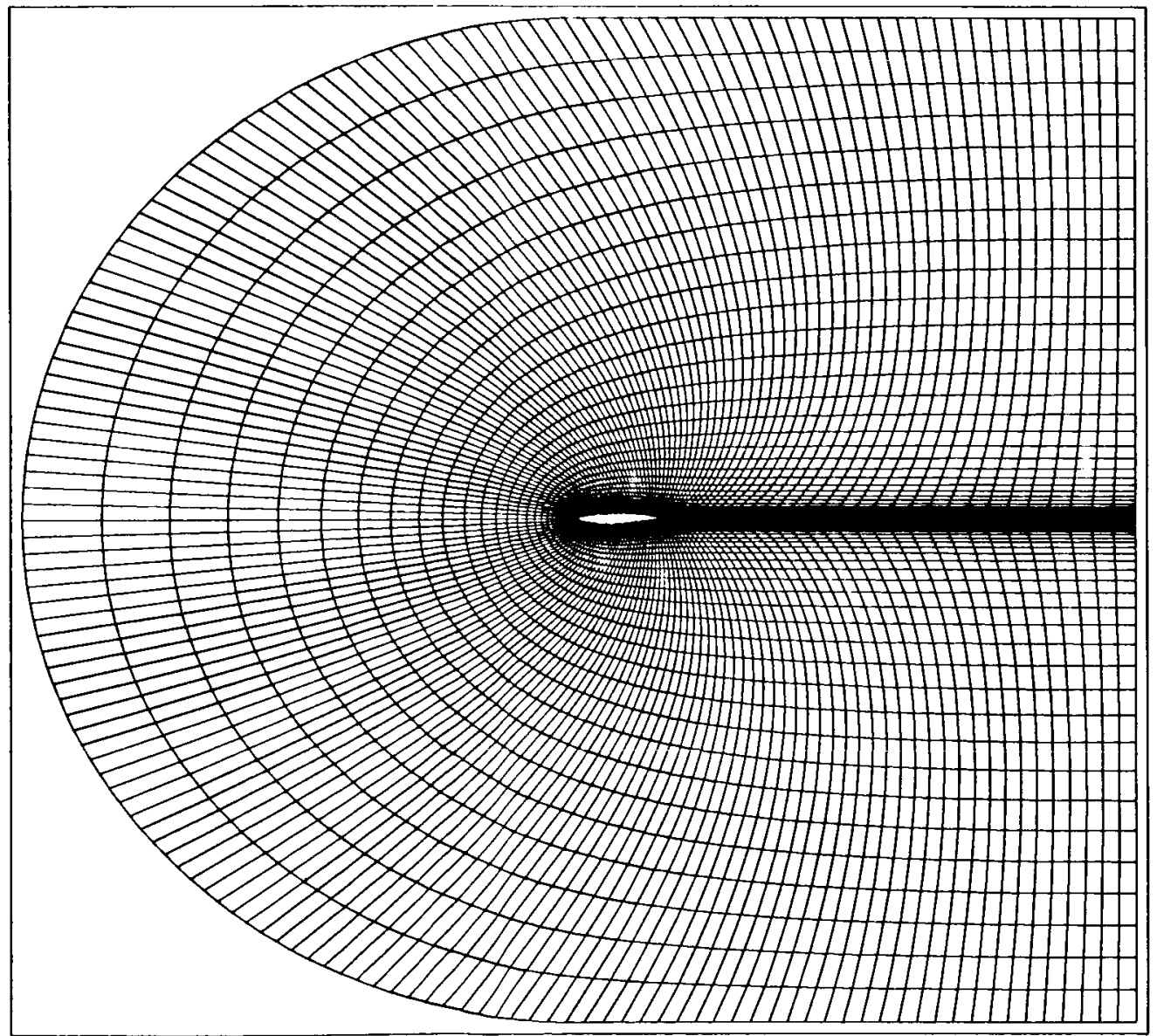

FIGURE 2. - $157 \times 58$ BASE GRID USED IN COMPUTATIONS, AVERAGE OUTER BOUNDARY DISTANCE EQUALS SIX CHORDS. 


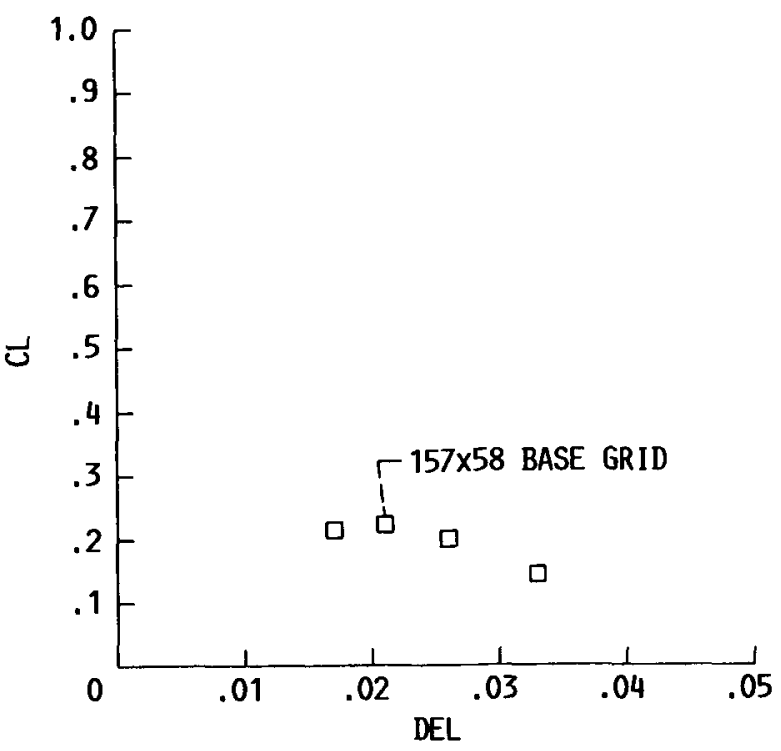

FIGURE 3. - PREDICTED CL VERSUS DEL. NACA 0012 AIRFOIL: MINF $=0.70$ : $A=1.49 ; \operatorname{Re}=9.00 \times 10^{6}$.

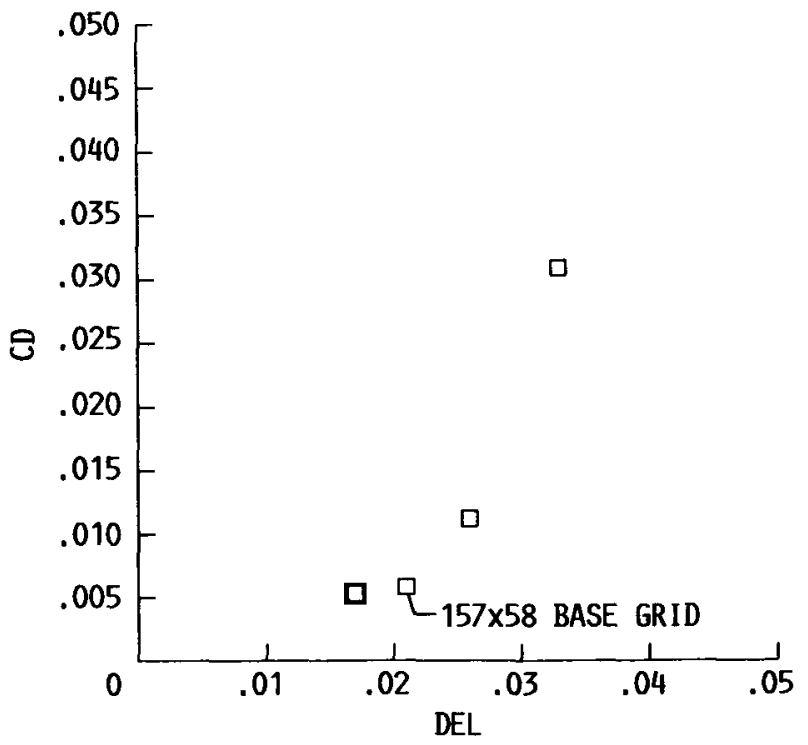

FIGURE 4. - PREDICTED CD VERSUS DEL. NACA 0012 AIRFOIL: MINF $=0.70$ : $A=1.49 ; \operatorname{Re}=9.00 \times 10^{6}$. 


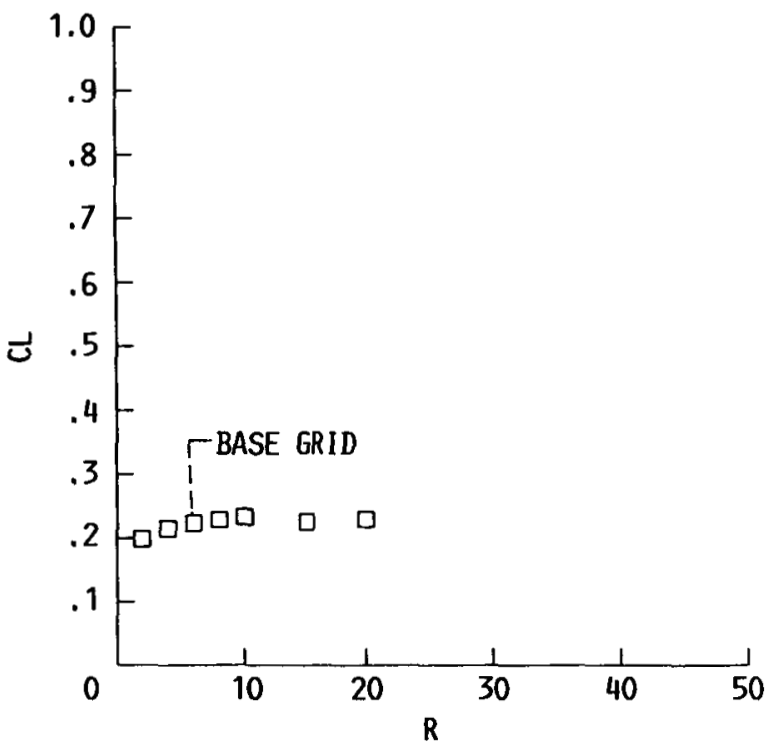

FIGURE 5. - PREDICTED CL VERSUS R. NACA 0012 AIRFOIL: MINF $=0.70 ; A=1.49$; $R e=9.00 \times 10^{6}$.

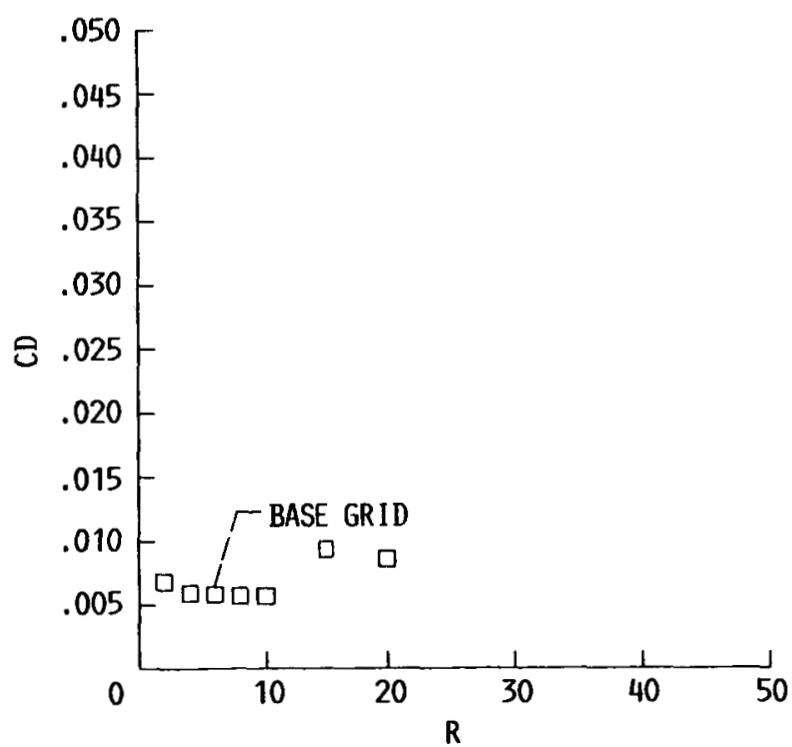

FIGURE 6. - PREDICTED CD VERSUS R. NACA 0012 AIRFOIL; MINF $=0.70 ; A=1.49 ;$ $R e=9.00 \times 10^{6}$. 


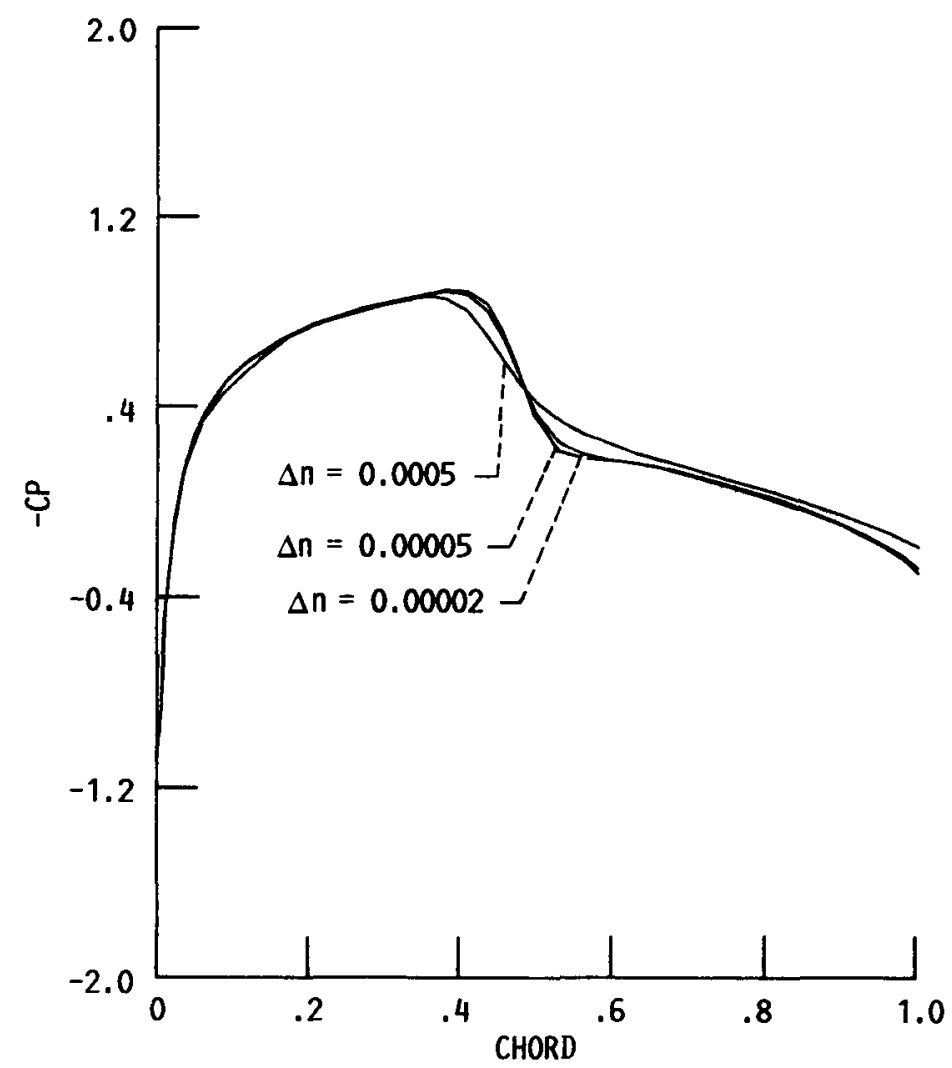

FIGURE 7.- EFFECT OF GRID SPACING NORMAL TO THE AIRFOIL SURFACE ON PRESSURE DISTRIBUTIONS, NACA 0012 AIRFOIL, MINF $=8.80, \operatorname{Re}=9.00 \times 10^{6}$. 


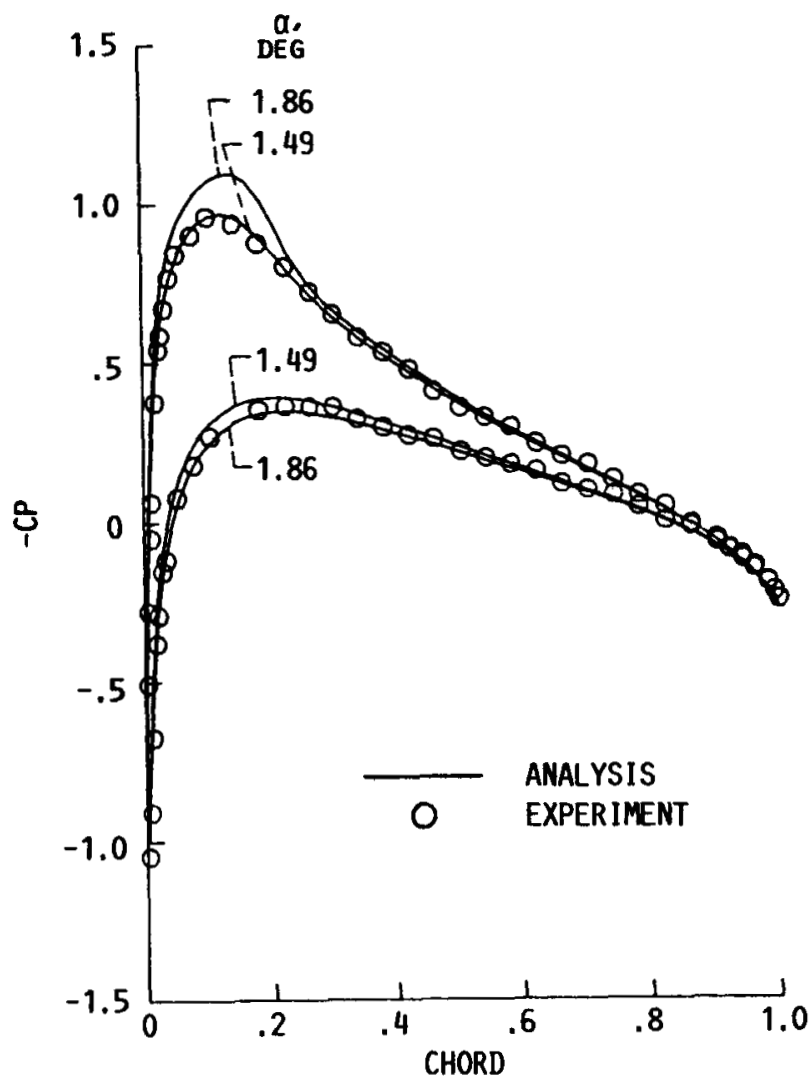

FIGURE 8. - PRESSURE DISTRIBUTIONS ON NACA 0012 AIRFOIL. MINF $=0.70$ : $A=1.86(1.49) ; \operatorname{Re}=9.00 \times 10^{6}$. 


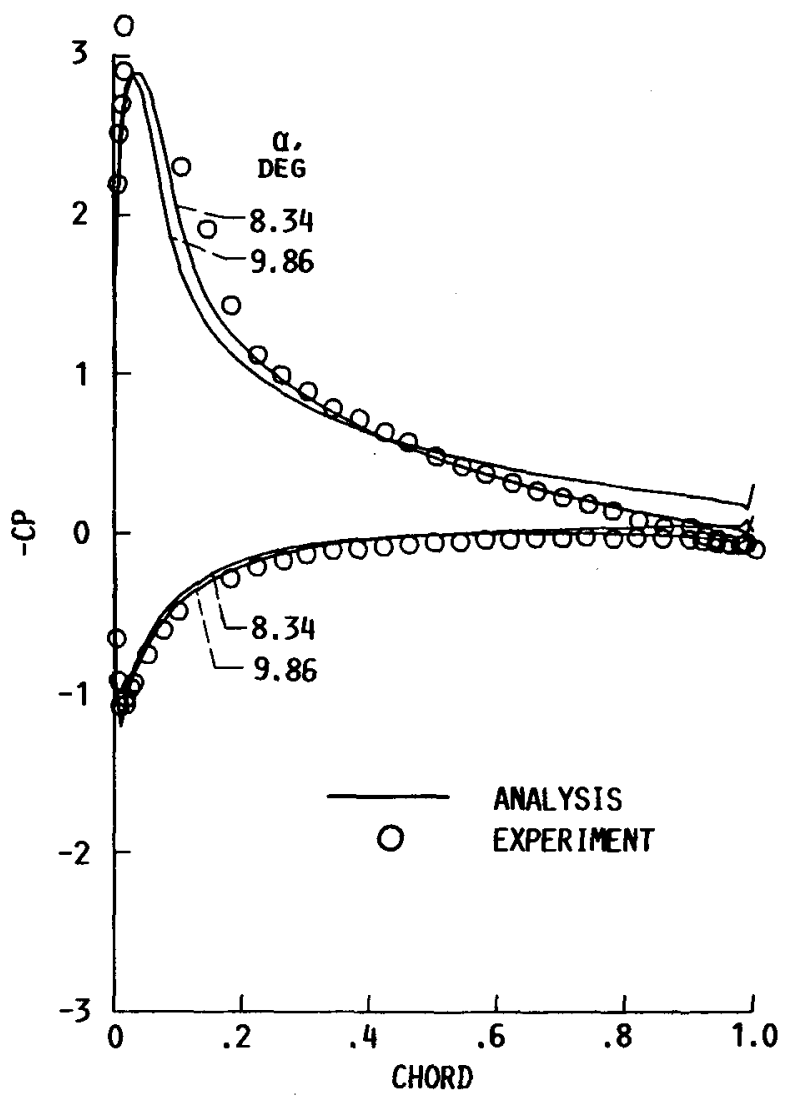

FIGURE 9, - PRESSURE DISTRIBUTIONS ON NACA 0012 AIRFOIL. MINF $=0.55$ : $A=9.86(8.34): \operatorname{Re}=9.00 \times 10^{6}$. 


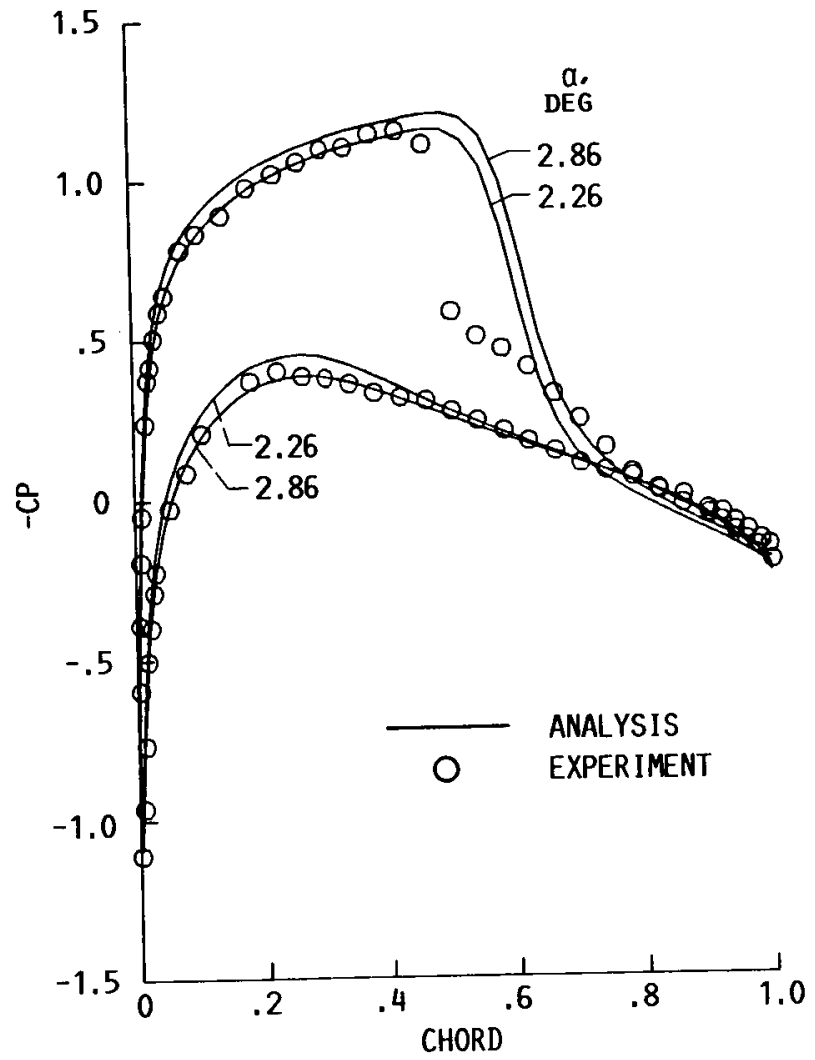

FIGURE 10. - PRESSURE DISTRIBUTIONS ON NACA 0012 AIRFOIL. MINF $=0.799$; $A=2.86(2.26) ; \operatorname{Re}=9.00 \times 10^{6}$. 


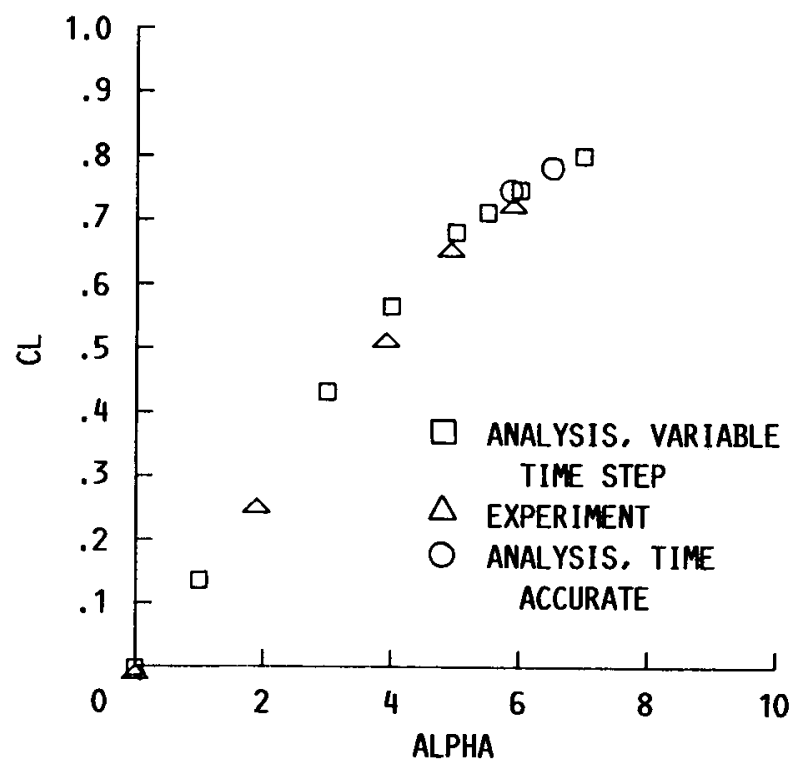

FIGURE 11. - CL VERSUS ALPHA. NACA 0012 AIRFOIL: MINF $=0.70: \operatorname{Re}=9.00 \times 10^{6}$.

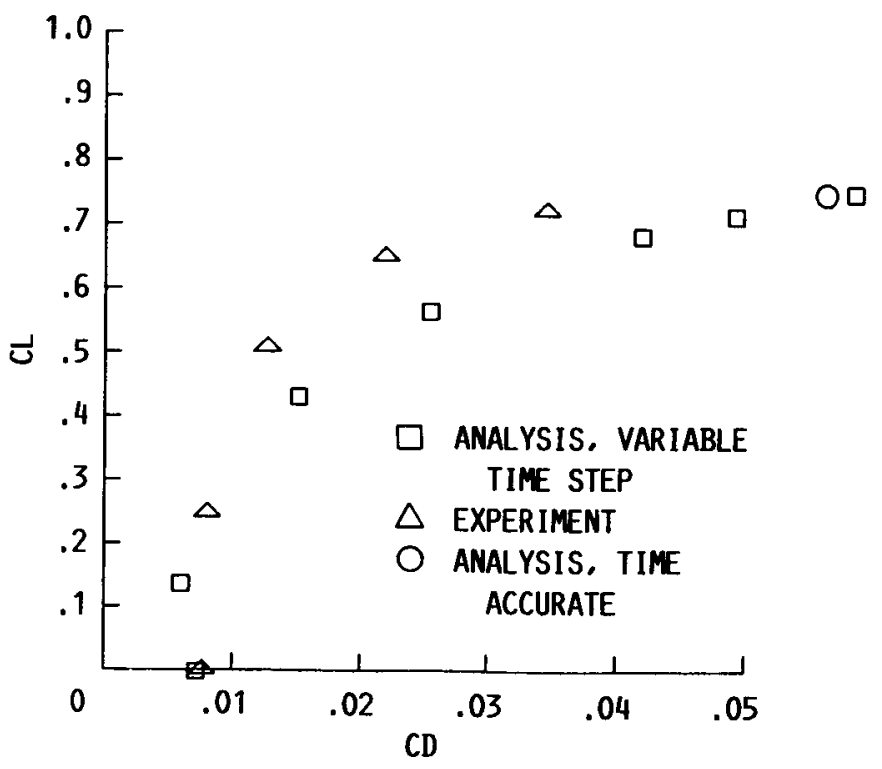

FIGURE 12. - CL VERSUS CD. NACA 0012 AIRFOIL: MINF $=0.70 ; \operatorname{Re}=9.00 \times 10^{6}$. 


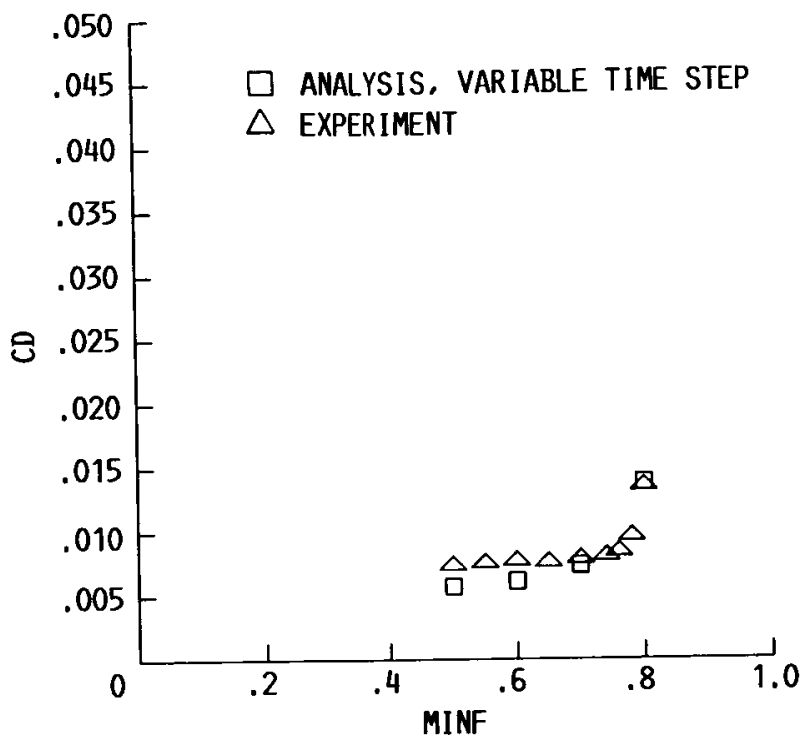

FIGURE 13. - CD VERSUS MINF. NACA 0012 AIRFOIL: $A=0 ; \operatorname{Re}=9.00 \times 10^{6}$.

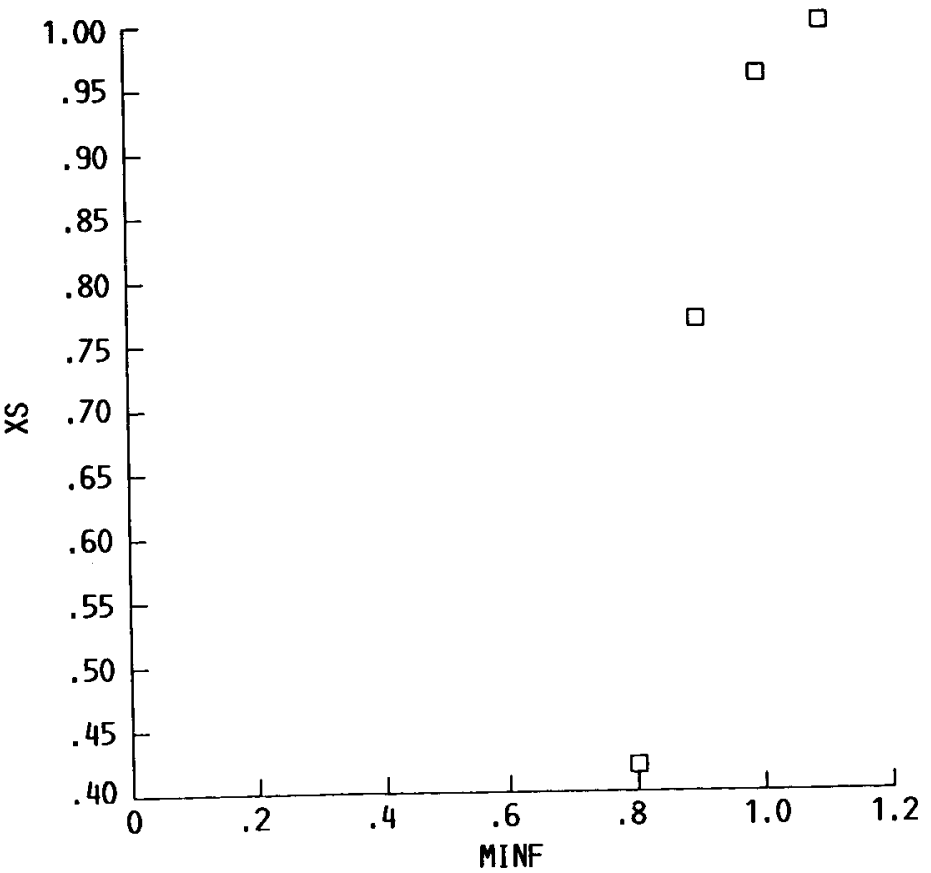

FIGURE 14. - PREDICTED SHOCK WAVE LOCATION VERSUS MINF. NACA 0012 AIRFOIL; $A=0$ : $\operatorname{Re}=9.00 \times 10^{6}$. 


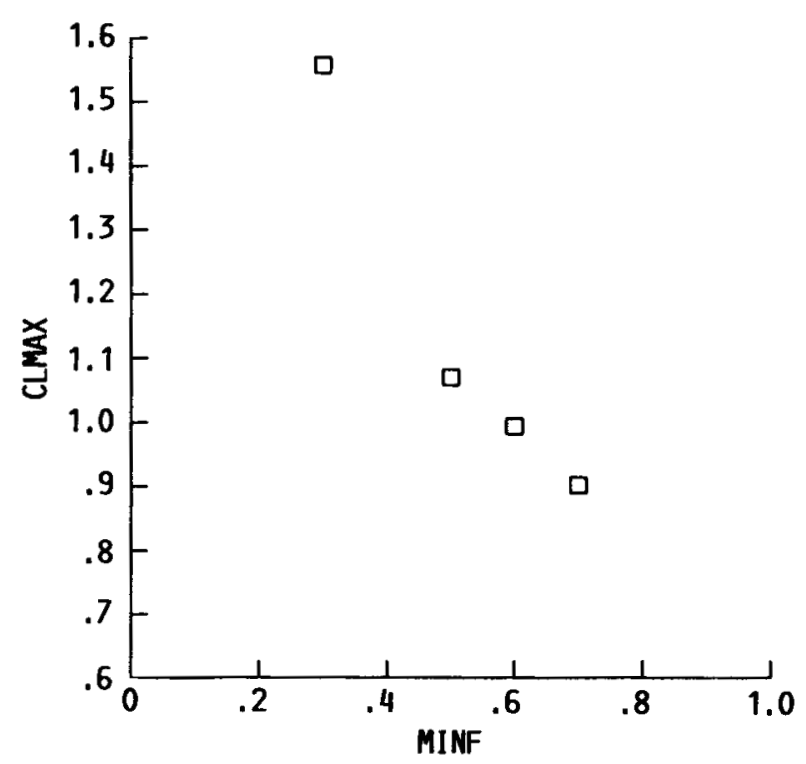

FIGURE 15. - PREDICTED CLMAX VERSUS MINF. NACA 0012 AIRFOIL; Re $=9.00 \times 10^{6}$.

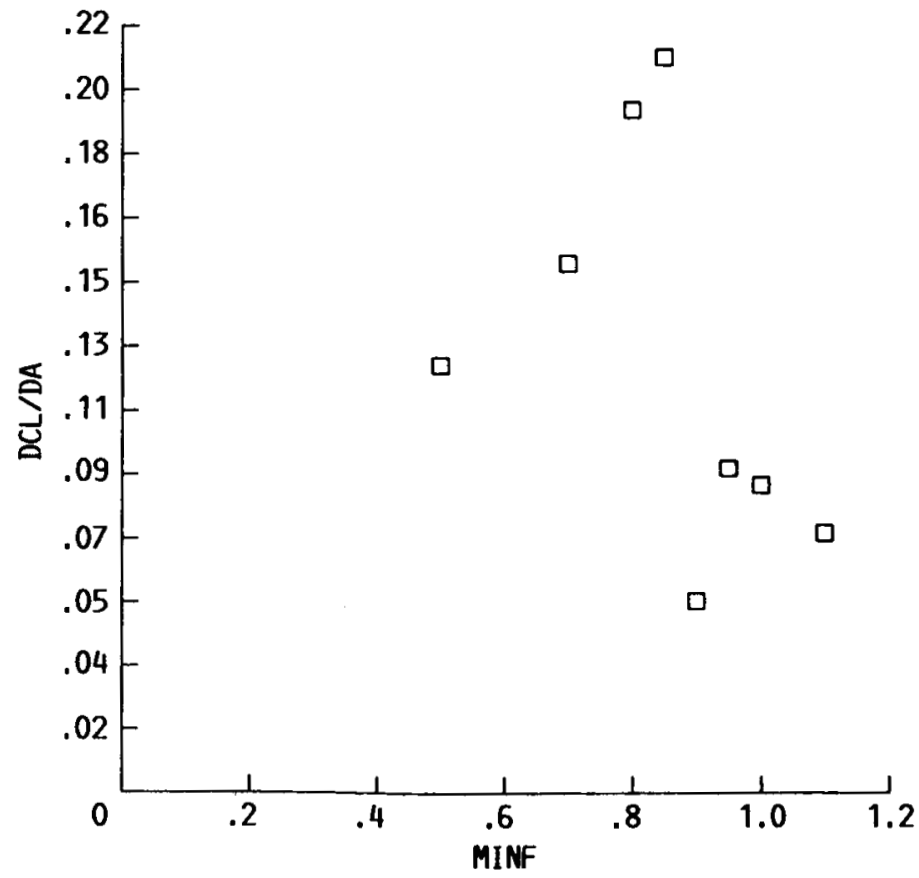

FIGURE 16. - PREDICTED DCL/DA VERSUS MINF. NACA 0012 AIRFOIL; $A=0 ; \operatorname{Re}=9.00 \times 10^{6}$. 


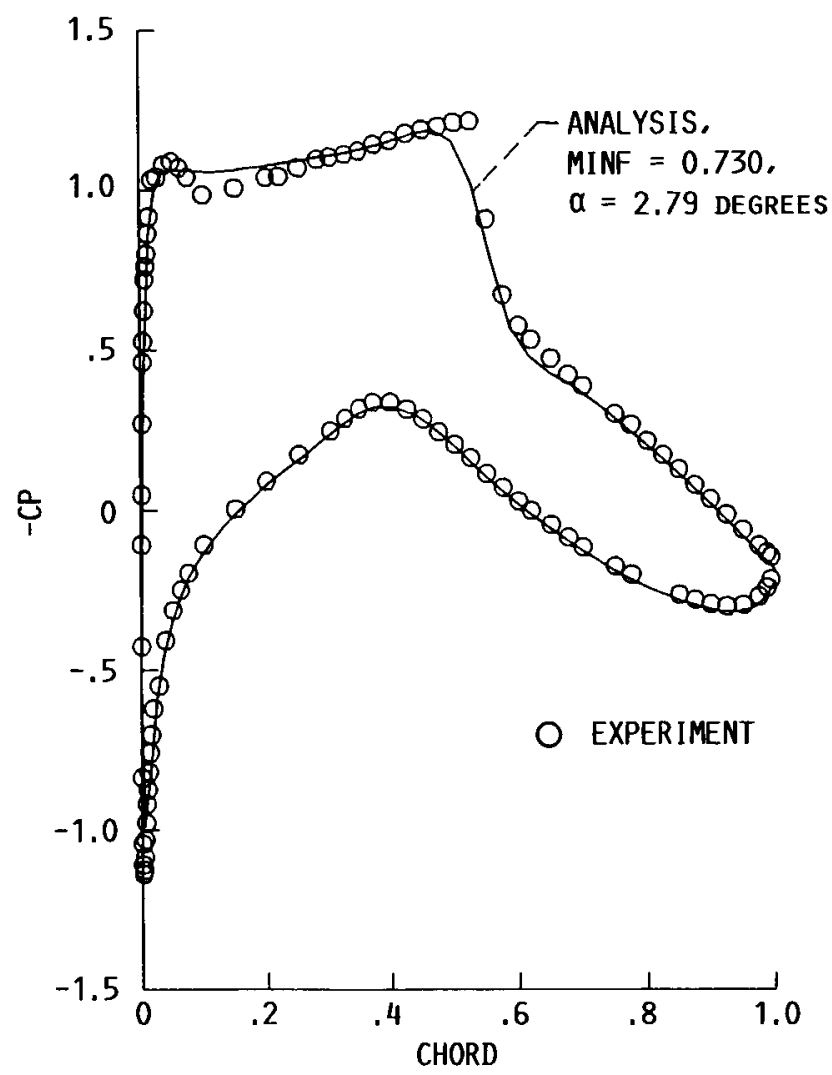

FIGURE 17. - PRESSURE DISTRIBUTIONS ON RAE 2822 AIRFOIL. MINF $=0.725$; $A=2.92 ; \operatorname{Re}=6.50 \times 10^{6}$.

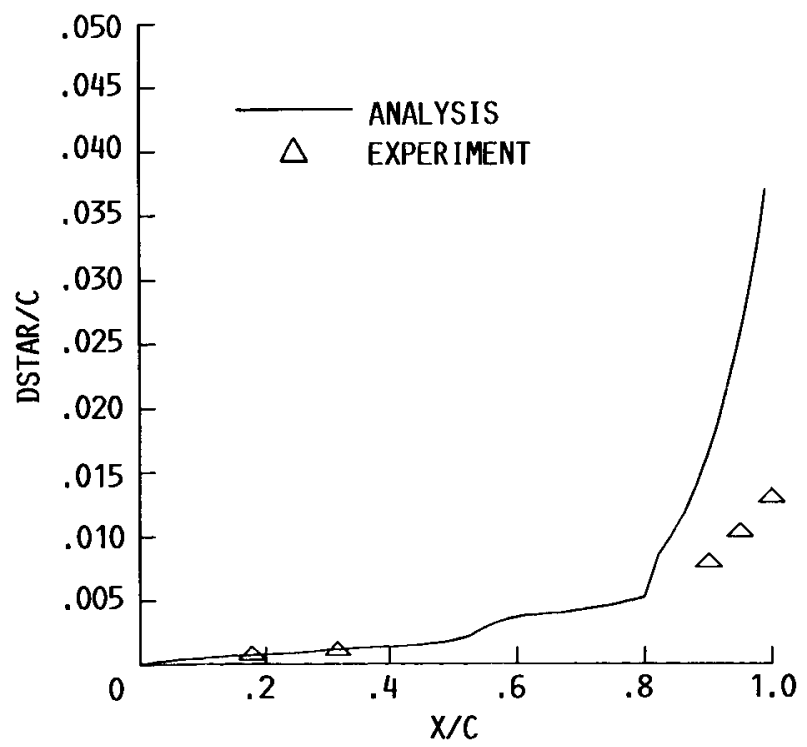

FIGURE 18. - DISPLACENENT THICKNESS ON UPPER SURFACE OF RAE 2822 AIRFOIL. $A=2.92 ;$ MINF $=0.725: \operatorname{Re}=6.50 \times 10^{6}$. 


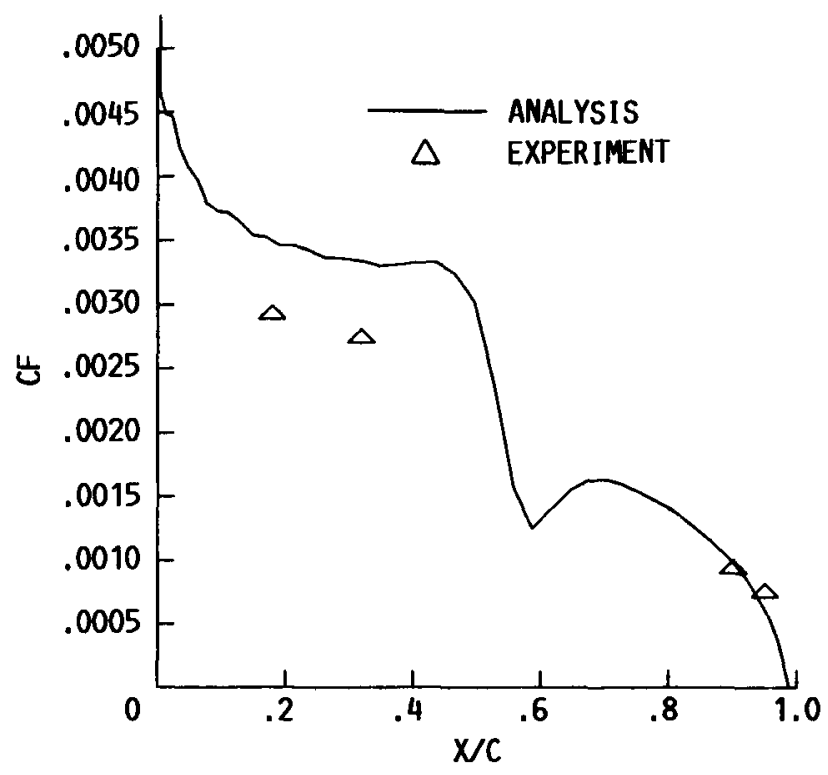

FIGURE 19. - SKIN FRICTION COEFFICIENT ON UPPER SURFACE OF RAE 2822 AIRFOIL. $A=2.92 ;$ MINF $=0.725: \operatorname{Re}=6.50 \times 10^{6}$.

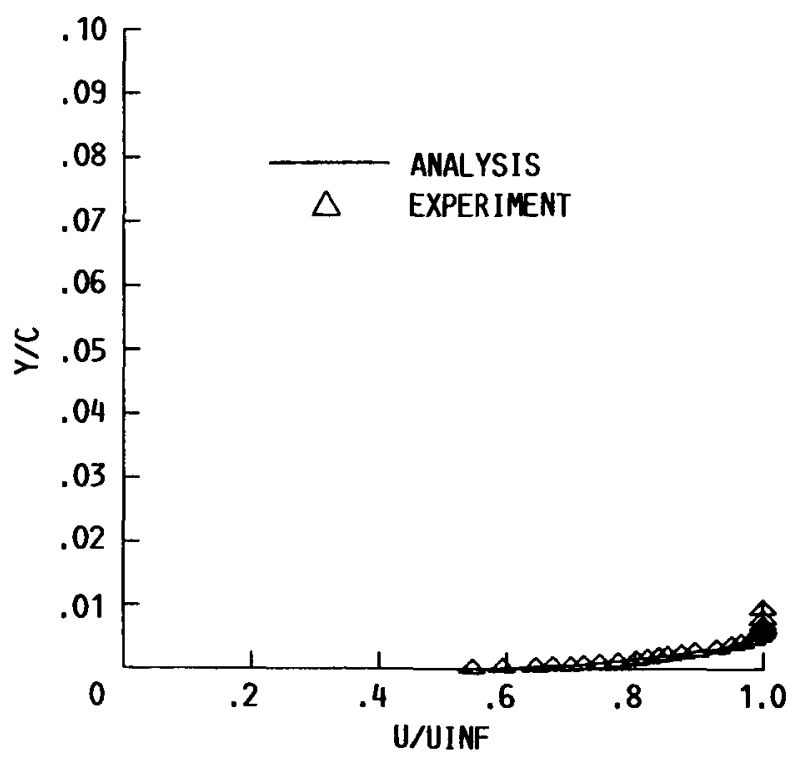

FIGURE 20. - VELOCITY PROFILE AT $X / C=0.319$. UPPER SURFACE OF RAE 2822 AIRFOIL: $A=2.92$; MINF $=0.725: \operatorname{Re}=6.50 \times 10^{6}$. 


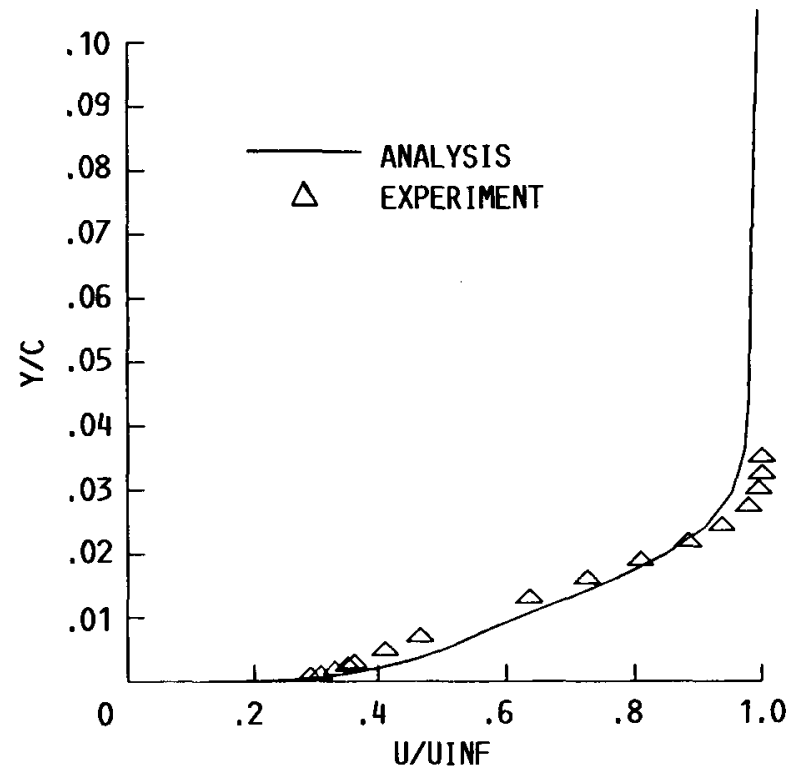

FIGURE 21. - VELOCITY PROFILE AT $X / C=0.95$. UPPER SURFACE OF RAE 2822 AIRFOIL; $A=2.92$; MINF $=0.725, \operatorname{Re}=6.50 \times 10^{6}$. 


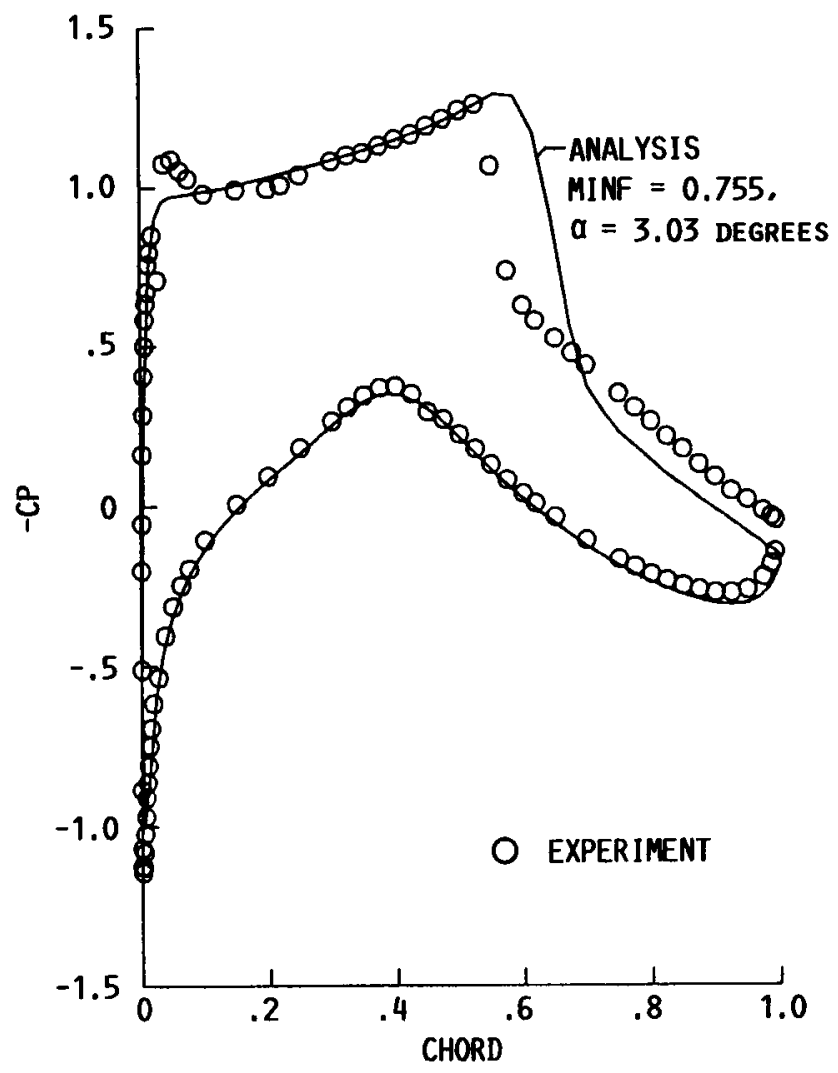

FIGURE 22. - PRESSURE DISTRIBUTIONS ON RAE 2822 AIRFOIL. MINF $=0.750: A=3.19$; $\operatorname{Re}=6.20 \times 10^{6}$. 


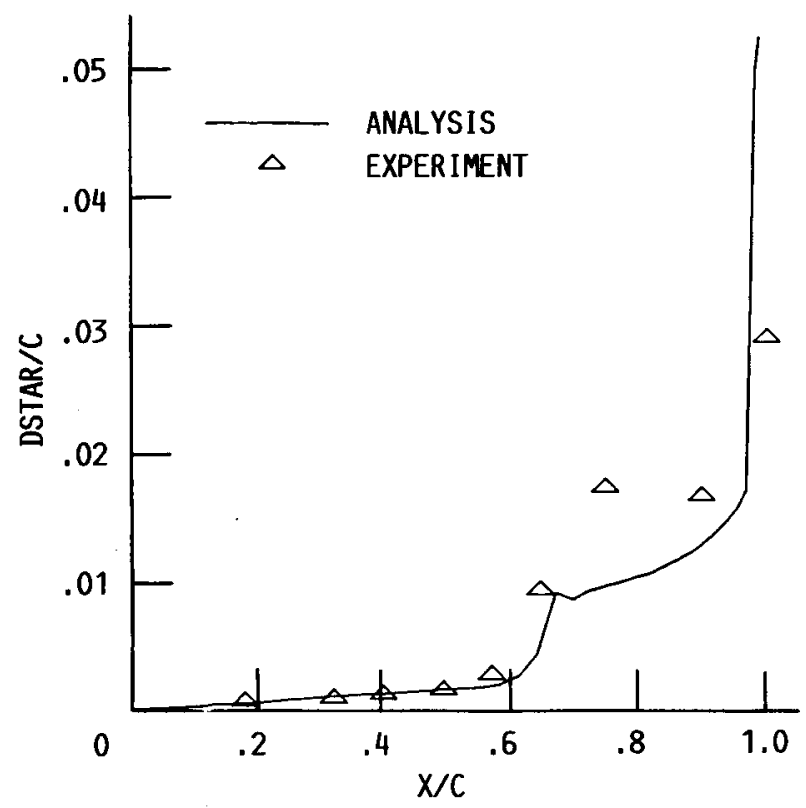

FIGURE 23.- DISPLACEMENT THICKNESS ON UPPER SURFACE OF RAE 2822 AIRFOIL. $A=3.19$. MINF $=0.750, R e=6.20 \times 10^{6}$.

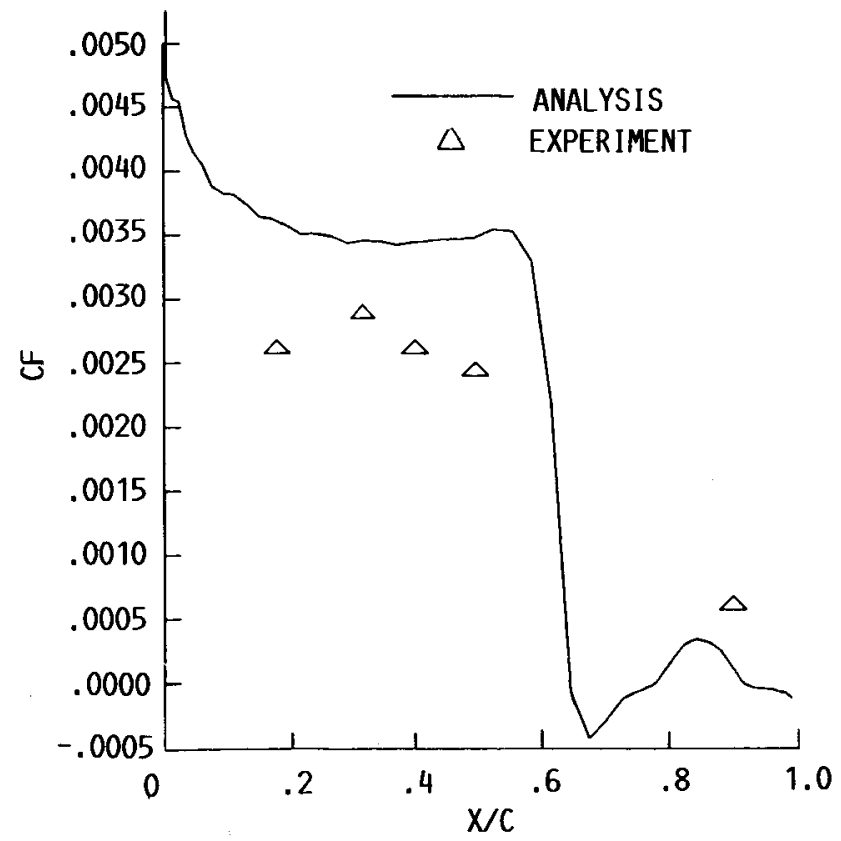

FIGURE 24. - SKIN FRICTION COEFFICIENT ON UPPER SURFACE OF RAE 2822 . AIRFOIL. $A=3.19 ;$ MINF $=0.750: \operatorname{Re}=6.20 \times 10^{6}$. 


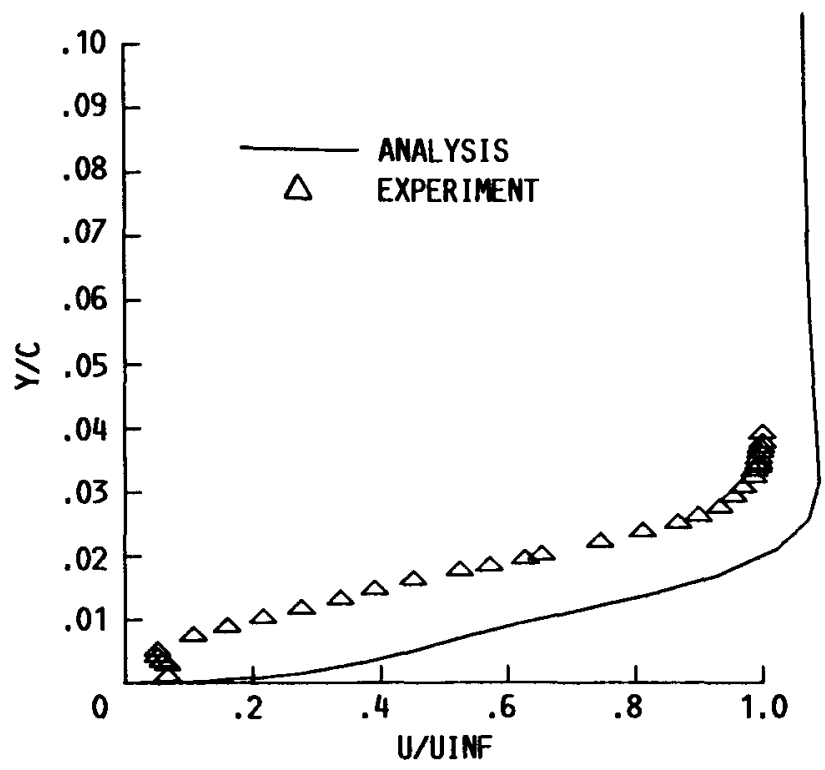

FIGURE 25. - VELOCITY PROFILE AT $X / C=0.750$. UPPER SURFACE OF RAE 2822 AIRFOIL; $A=3.19$;

MINF $=0.750 ; \operatorname{Re}=6.20 \times 10^{6}$.

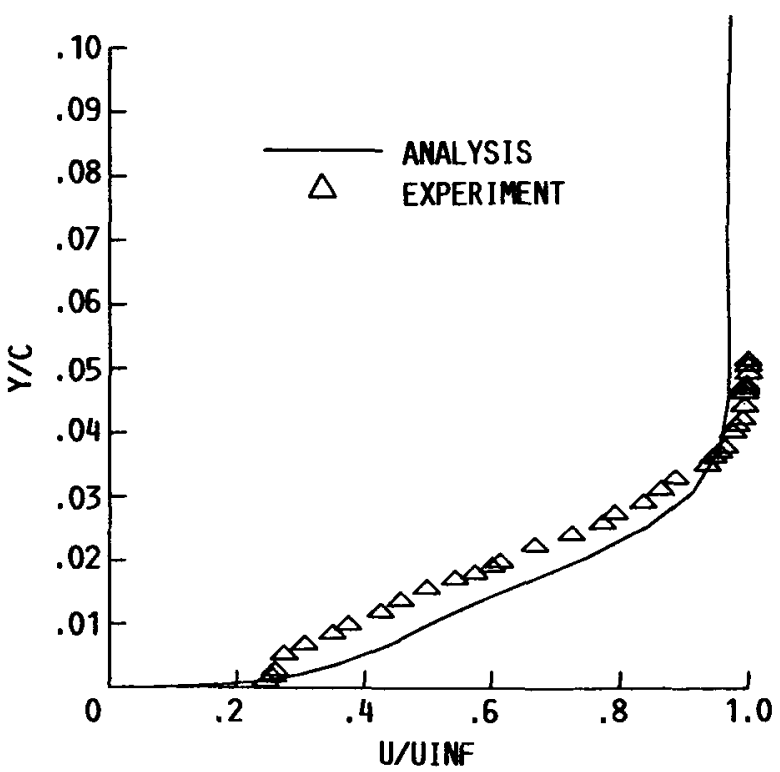

FIGURE 26. - VELOCITY PROFILE AT $X / C=0.90$. UPPER SURFACE OF RAE 2822 AIRFOIL; $A=3.19$; MINF $=0.750 ; \operatorname{Re}=6.20 \times 10^{6}$. 


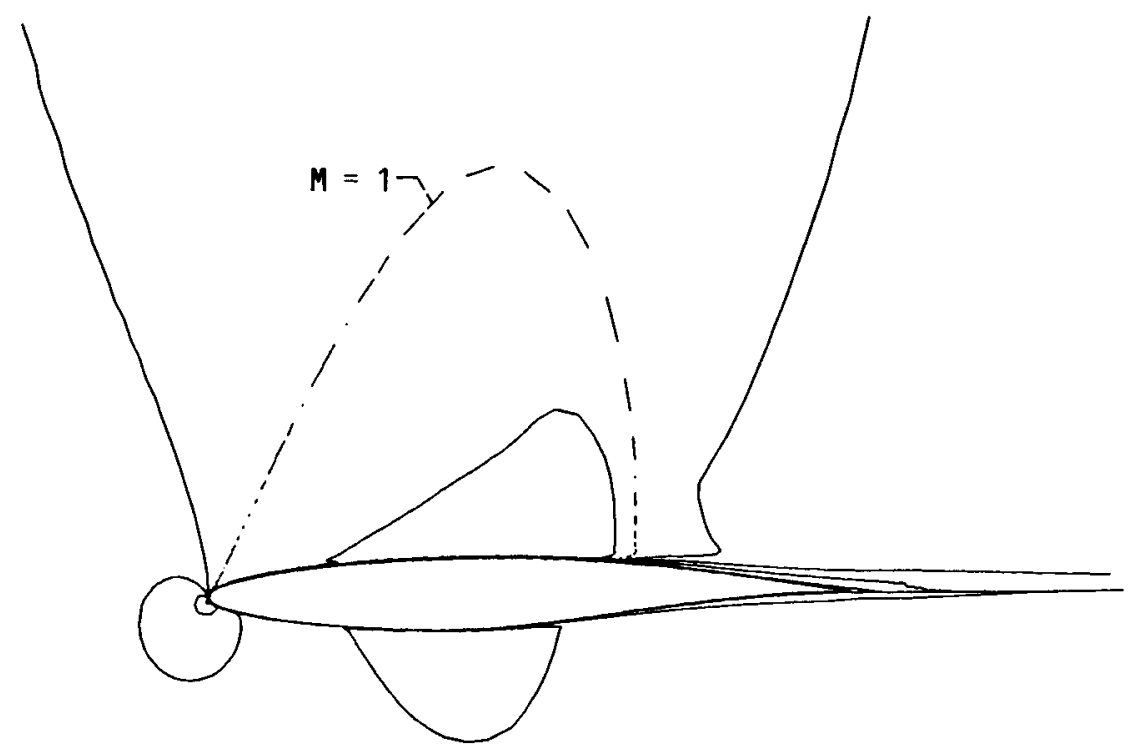

FIGURE 27. - SONIC LINE PREDICTION FOR RAE 2822 AIRFOIL. $A=3.19 ;$ MINF $=0.75 ; \operatorname{Re}=6.20 \times 10^{6}$.

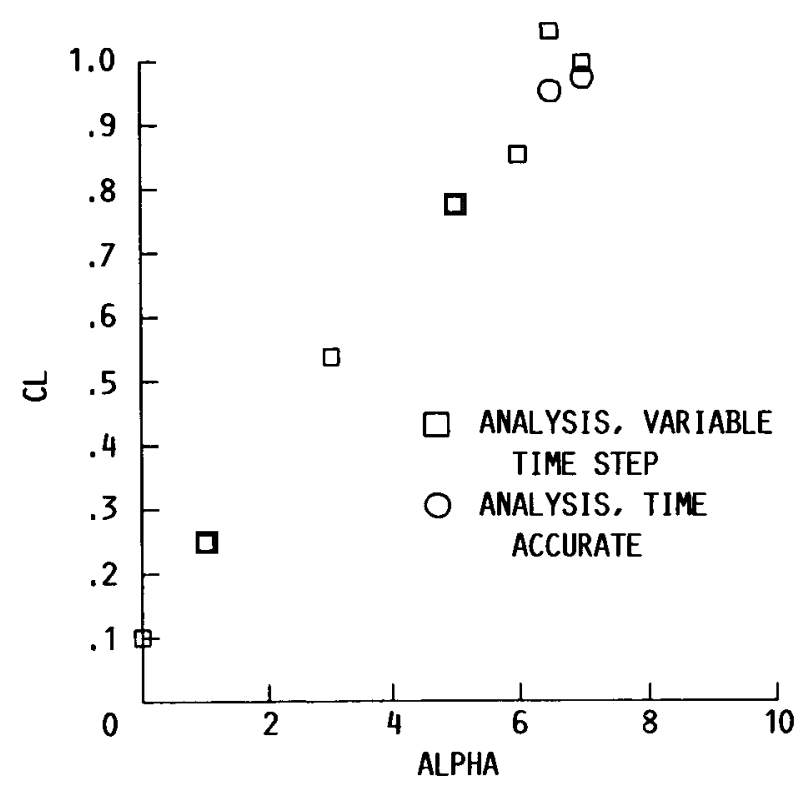

FIGURE 28. - PREDICTED CL VERSUS ALPHA.

JONES AIRFOIL: MINF $=0.70$;

$\operatorname{Re}=9.00 \times 10^{6}$. 


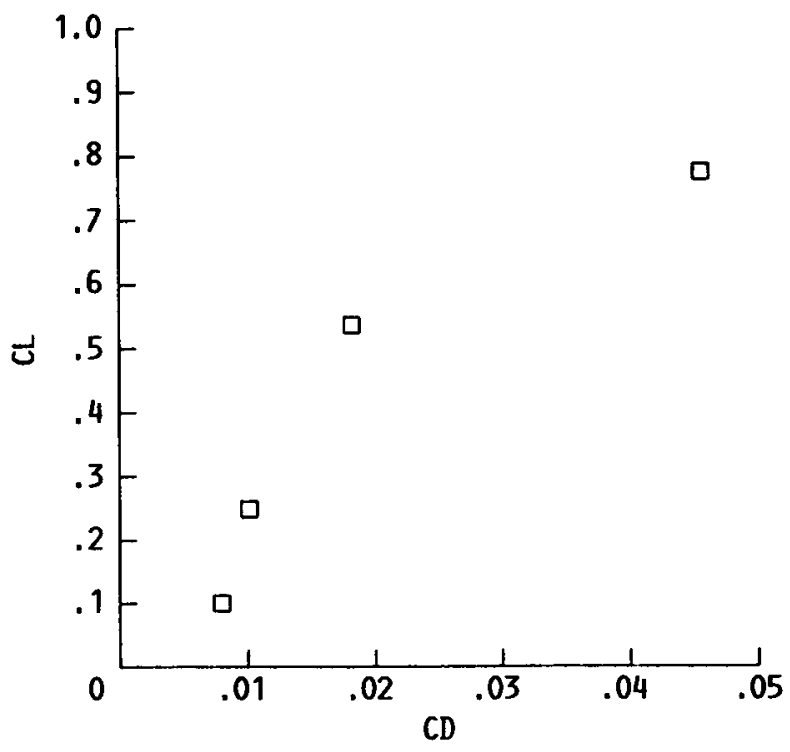

FIGURE 29. - PREDICTED CL VERSUS CD.

JONES AIRFOIL: MINF $=0.70$ :

$R e=9.00 \times 10^{6}$.

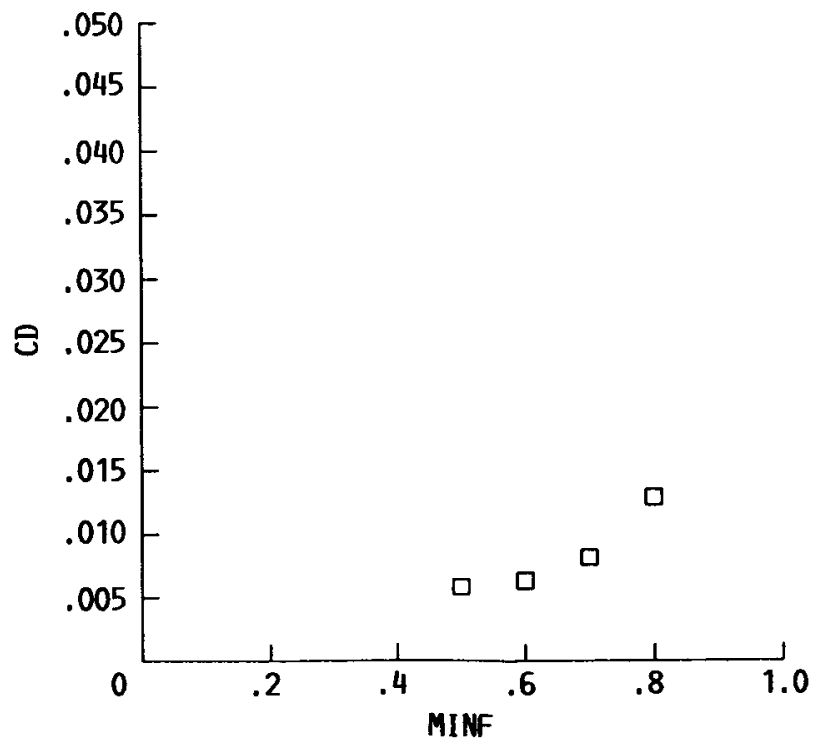

FIGURE 30. - PREDICTED CD VERSUS MINF.

JONES AIRFOIL: $A=0 ; \operatorname{Re}=9.00 \times 10^{6}$. 


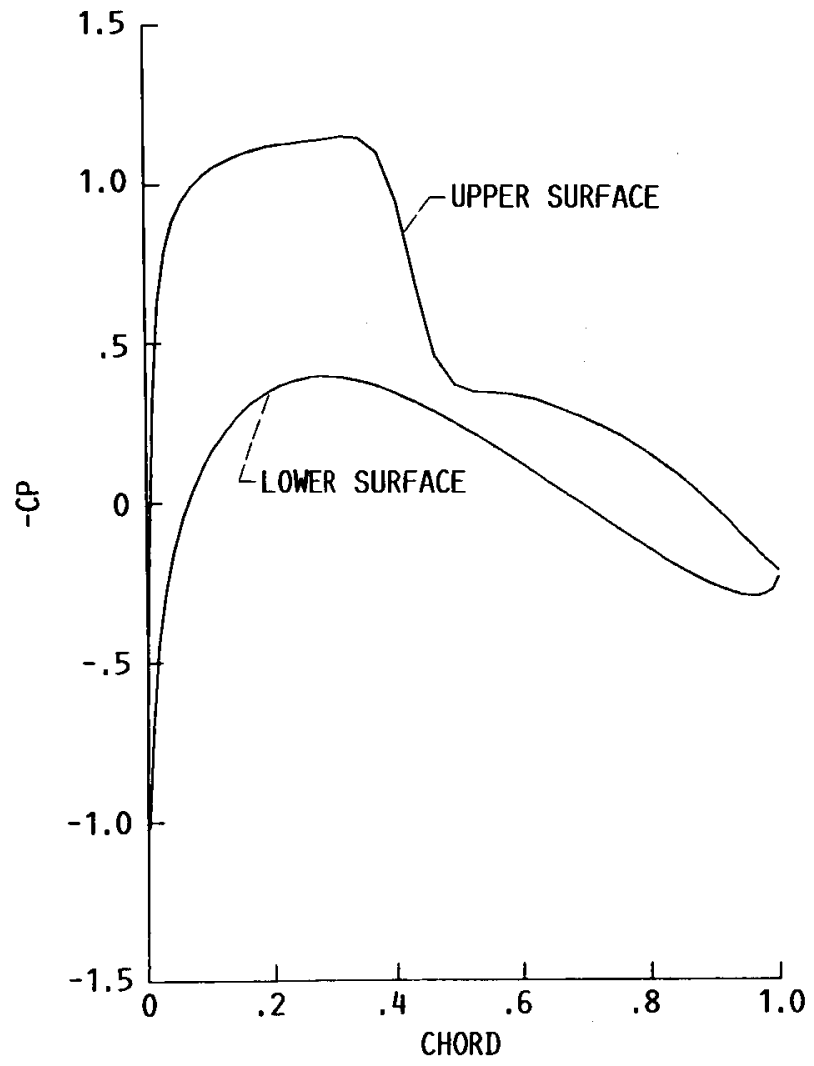

FIGURE 31. - PREDICTED PRESSURE DISTRIBUTIONS ON JONES AIRFOIL. MINF $=0.75$ $A=2.00 ; \operatorname{Re}=9.00 \times 10^{6}$. 


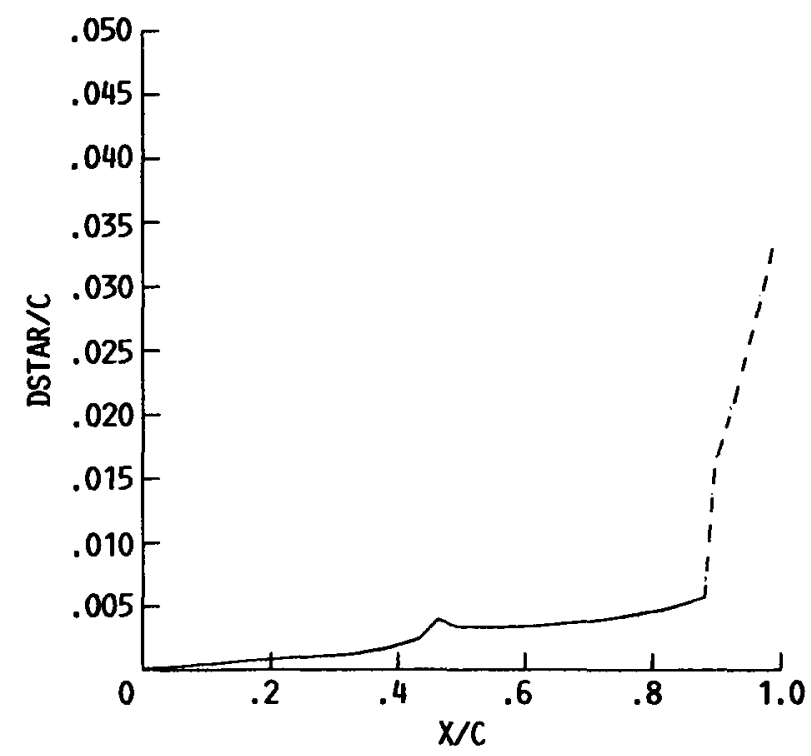

FIGURE 32. - PREDICTED DISPLACEMENT THICKNESS ON UPPER SURFACE OF JONES AIRFOIL. $A=2.00 ;$ MINF $=0.75: \operatorname{Re}=9.00 \times 10^{6}$.

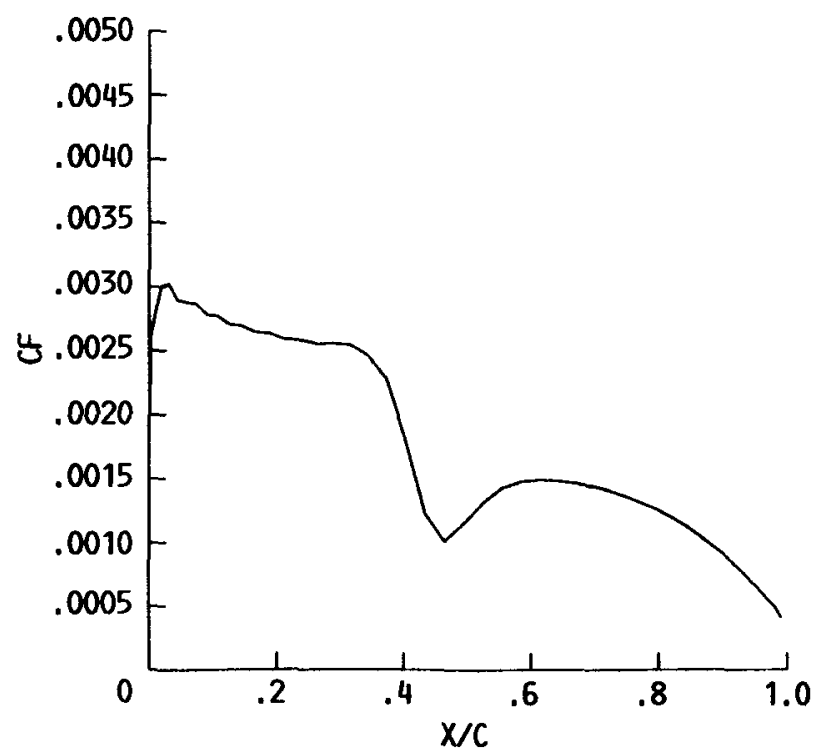

FIGURE 33. - PREDICTED SKIN FRICTION COEFFICIENT ON UPPER SURFACE OF JONES AIRFOIL. $A=2.00:$ MINF $=0.75$; $\operatorname{Re}=9.00 \times 10^{6}$. 


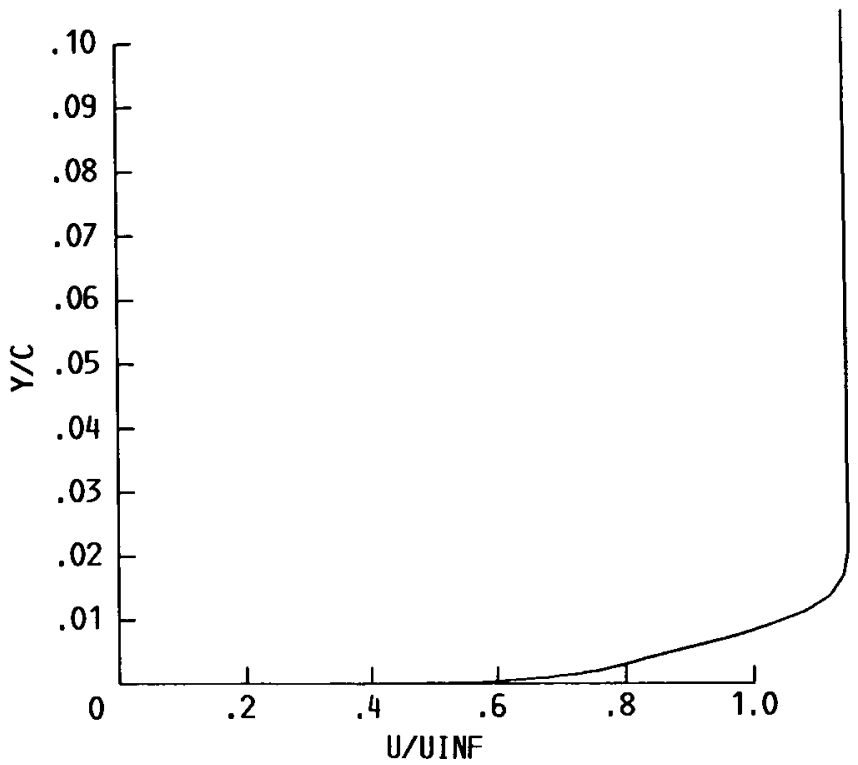

FIGURE 34. - PREDICTED VELOCITY PROFILE AT $X / C=0.6$. UPPER SURFACE OF JONES AIRFOIL; $A=2.00$; $M I N F=0.75$; $R e=9.00 \times 10^{6}$.

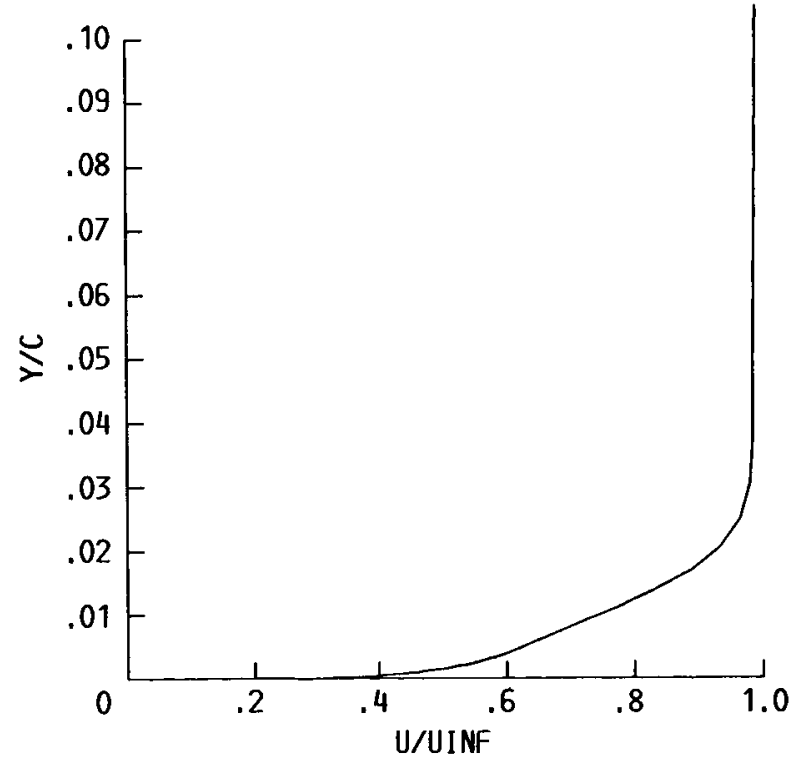

FIGURE 35. - PREDICTED VELOCITY PROFILE AT $X / C=0.9$. UPPER SURFACE OF JONES AIRFOIL: $A=2.00 ;$ MINF $=0.75$ : $\operatorname{Re}=9.00 \times 10^{6}$. 


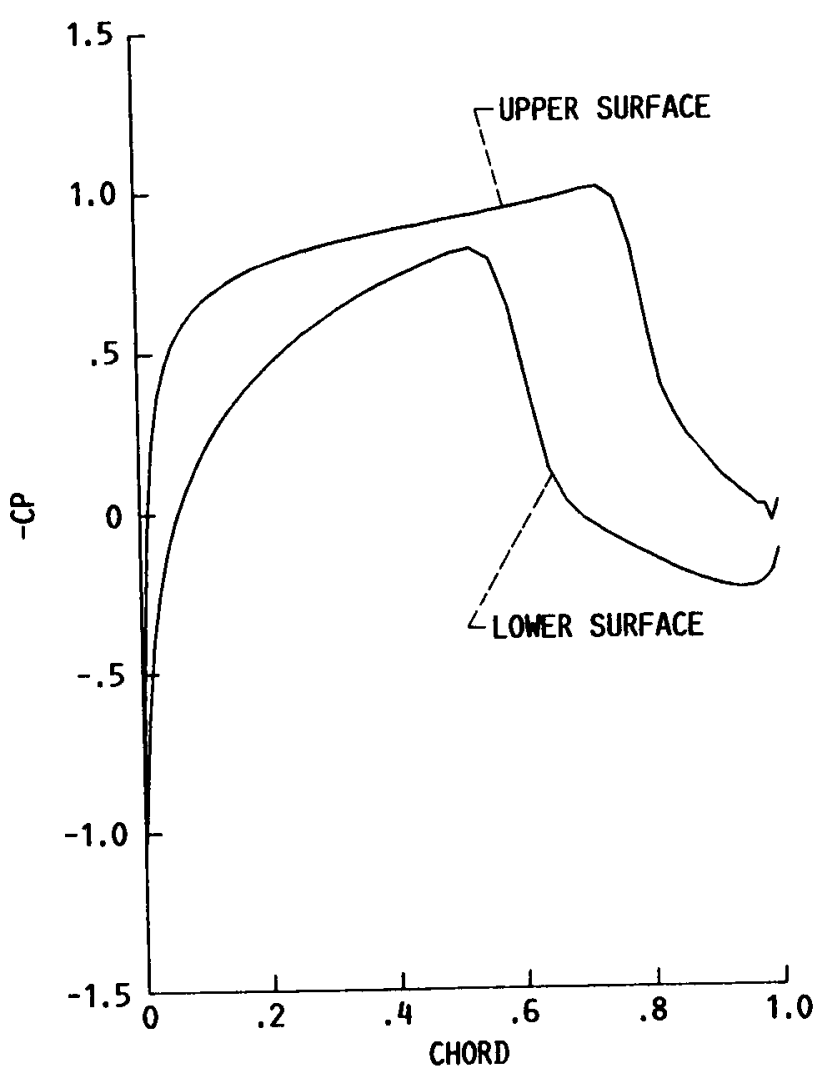

FIGURE 36. - PREDICTED PRESSURE DISTRIBUTIONS ON JONES AIRFOIL. MINF $=0.85$; $A=2.00 ; \operatorname{Re}=9.00 \times 10^{6}$.

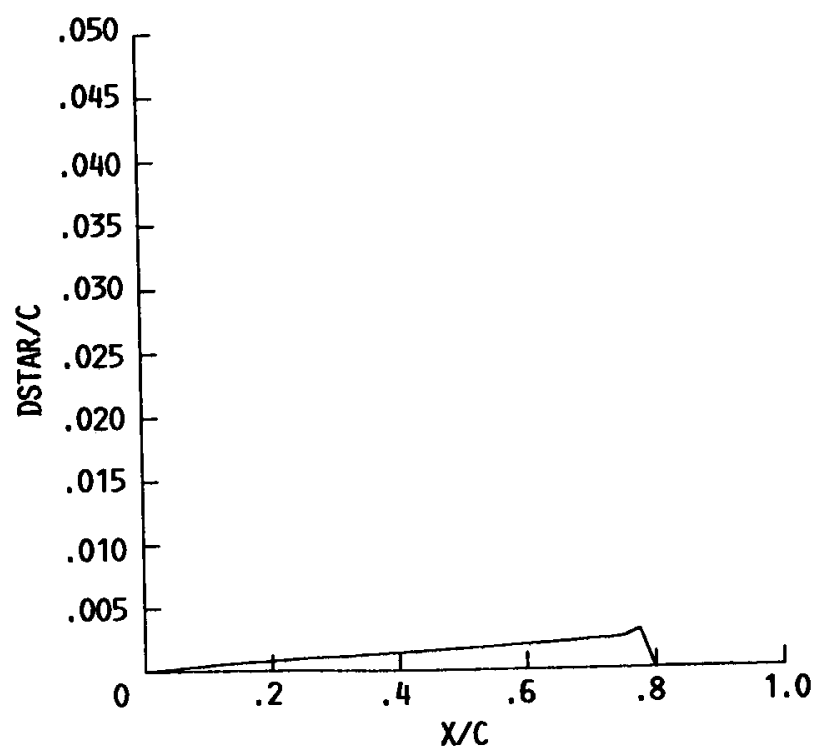

FIGURE 37. - PREDICTED DISPLACEMENT THICKNESS ON UPPER SURFACE OF JONES AIRFOIL. $A=2.00: \operatorname{MINF}=0.85: \operatorname{Re}=9.00 \times 10^{6}$. 


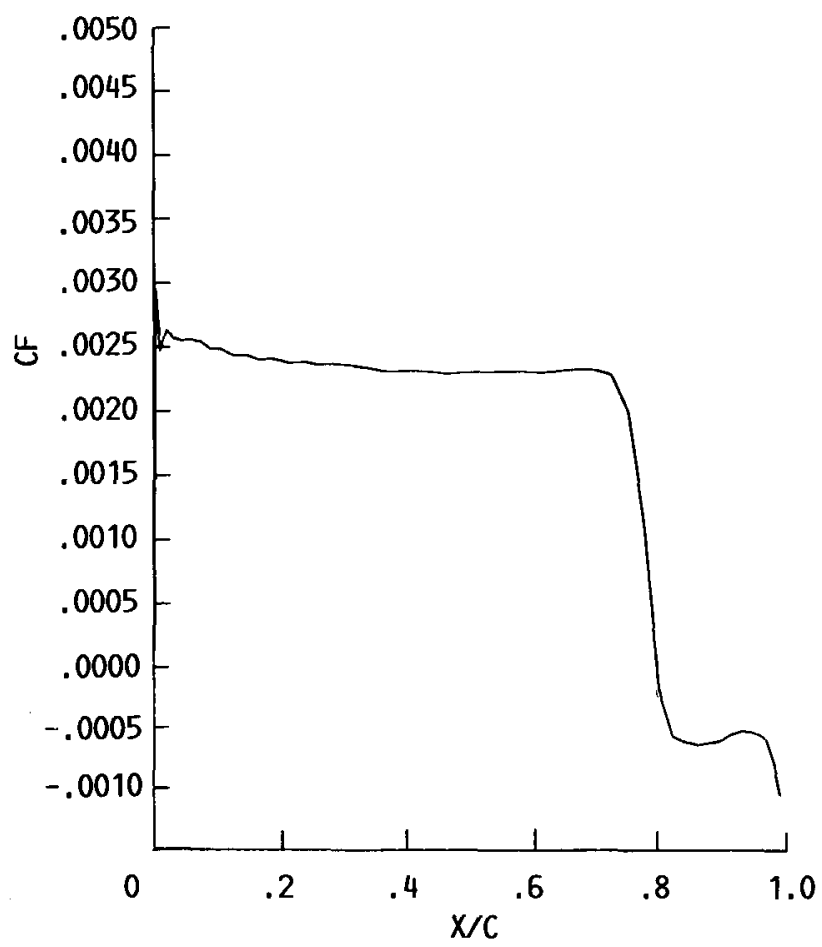

FIGURE 38. - PREDICTED SKIN FRICTION COEFFICIENT ON UPPER SURFACE OF JONES AIRFOIL. $A=2.00 ;$ MINF $=0.85$; $\operatorname{Re}=9.00 \times 10^{6}$.

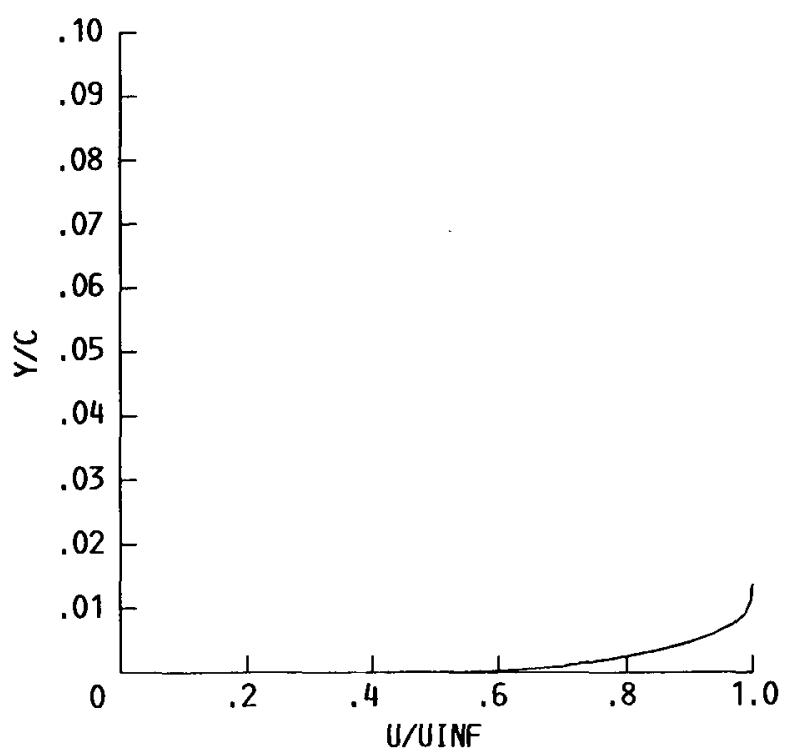

FIGURE 39. - PREDICTED VELOCITY PROFILE AT $X / C=0.6$. UPPER SURFACE OF JONES AIRFOIL; $A=2.00 ;$ MINF $=0.85$; $\operatorname{Re}=9.00 \times 10^{6}$. 


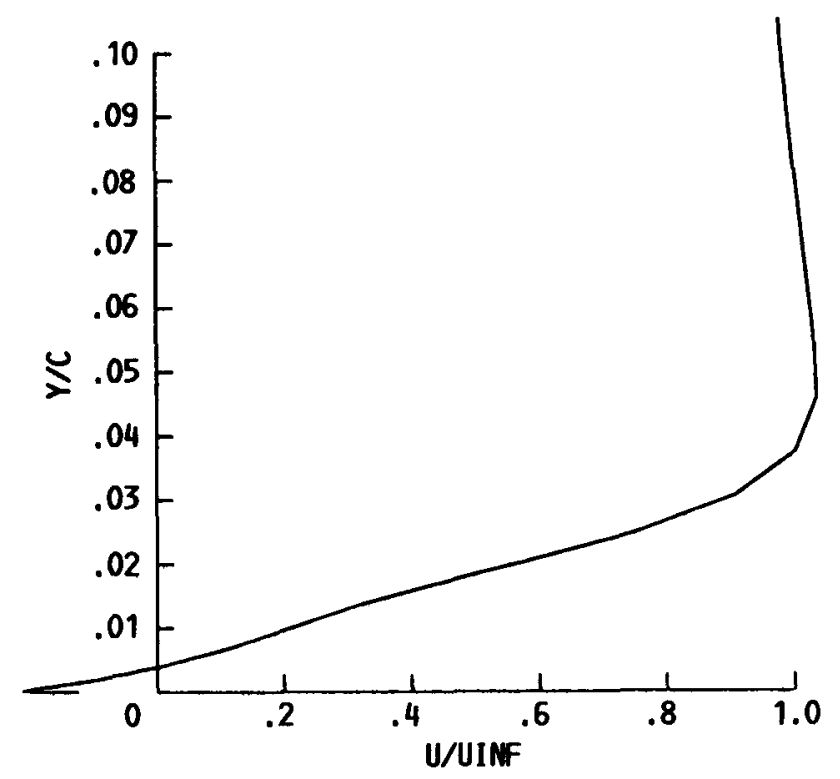

FIGURE 40. - PREDICTED VELOCITY PROFILE AT $X / C=0.9$. UPPER SURFACE OF JONES AIRFOIL: $A=2.00$; MINF $=0.85$; $\operatorname{Re}=9.00 \times 10^{6}$. 


\begin{tabular}{|c|c|c|c|}
\hline 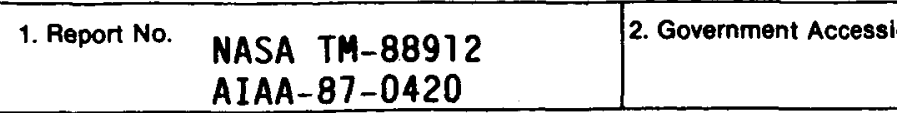 & \multirow{3}{*}{$\begin{array}{l}\text { 2. Government Accession No. } \\
\text { If Flow Over Airfo11 }\end{array}$} & \multicolumn{2}{|c|}{ 3. Recipient's Catalog No. } \\
\hline \multirow{2}{*}{$\begin{array}{l}\text { 4. Title and Subtitle } \\
\text { Analysis of Viscous Transontc Flow Over Airfoll } \\
\text { Sections }\end{array}$} & & \multicolumn{2}{|l|}{ 5. Report Date } \\
\hline & & $\begin{array}{r}\text { 6. Performing Orga } \\
535-03-01\end{array}$ & n Code \\
\hline \multirow{2}{*}{\multicolumn{2}{|c|}{$\begin{array}{l}\text { 7. Author(s) } \\
\text { Dennis L. Huff, Jiunn-Ch1 Wu, and L.N. Sankar }\end{array}$}} & \multicolumn{2}{|c|}{$\begin{array}{l}\text { 8. Performing Organization Report No. } \\
\text { E-3340 }\end{array}$} \\
\hline & & \multicolumn{2}{|l|}{ 10. Work Unit No. } \\
\hline \multirow{2}{*}{\multicolumn{2}{|c|}{$\begin{array}{l}\text { 9. Performing Organization Name and Address } \\
\text { National Aeronautics and Space Administration } \\
\text { Lewis Research Center } \\
\text { Cleveland, Ohio } 44135\end{array}$}} & \multirow{2}{*}{\multicolumn{2}{|c|}{ 11. Contract or Grant No. }} \\
\hline & & & \\
\hline \multirow{2}{*}{\multicolumn{2}{|c|}{$\begin{array}{l}\text { 12. Sponsoring Agency Name and Address } \\
\text { Nationa } 1 \text { Aeronautics and Space Administration } \\
\text { Washington, D.C. } 20546\end{array}$}} & \multicolumn{2}{|c|}{$\begin{array}{l}\text { 13. Type of Report and Period Covered } \\
\text { Technical Memorandum }\end{array}$} \\
\hline & & \multicolumn{2}{|c|}{ 14. Sponsoring Agency Code } \\
\hline \multicolumn{4}{|c|}{$\begin{array}{l}\text { 15. Supplementary Notes } \\
\text { Prepared for the } 25 \text { th Aerospace Sciences Meeting, sponsored by the American } \\
\text { Institute of Aeronautics and Astronautics, Reno, Nevada, January } 12-15 \text {, } 1987 \text {. } \\
\text { Dennis L. Huff, NASA Lewis Research Center; Jiunn-Chi Wu and L.N. Sankar, } \\
\text { Georgia Institute of Technology. School of Aerospace Engineering, Atlanta, } \\
\text { Georgia } 30332 \text {. }\end{array}$} \\
\hline \multicolumn{4}{|l|}{ 16. Abstract } \\
\hline \multicolumn{4}{|c|}{$\begin{array}{l}\text { A full Navier-Stokes solver has been used to model transonic flow over three } \\
\text { airfoil sections. The method uses a two-dimensional, implicit, conservative } \\
\text { finite difference scheme for solving the compressible Navier-Stokes equations. } \\
\text { Results are presented as prescribed for the Viscous Transonic Airfoil Workshop } \\
\text { to be held at the AIAA } 25 \text { th Aerospace Sciences Meeting. The NACA } 0012 \text {, RAE } 2822 \\
\text { and "Jones" airfoils have been investigated for both attached and separated } \\
\text { transonic flows. Predictions for pressure distributions, loads, skin friction } \\
\text { coefficients, boundary layer displacement thickness and velocity profiles are } \\
\text { included and compared with experimental data when possible. Overall, the results } \\
\text { are in good agreement with experimental data. }\end{array}$} \\
\hline $\begin{array}{l}\text { 17. Key Words (Suggested by Author(s)) } \\
\text { Navier-Stokes equations; Transonic flow; } \\
\text { Airfolls; Computational fluid dynamics }\end{array}$ & $\begin{array}{l}\text { 18. Distrib } \\
\text { Unc 1 } \\
\text { STAR }\end{array}$ & ory -34 & \\
\hline $\begin{array}{l}\text { 19. Security Classif. (of this report) } \\
\text { Unc las s if fed }\end{array}$ & ified & 21. No. of pages & 22. Price \\
\hline
\end{tabular}

*For sale by the National Technical Information Service, Springfield, Virginia 22161 